\title{
Isolation and Characterization of Pseudomonas spp. Strains That Efficiently Decompose Sodium Dodecyl Sulfate
}

Ewa M. Furmanczyk ${ }^{1}$, Michal A. Kaminski1, Grzegorz Spolnik², Maciej Sojka², Witold Danikiewicz ${ }^{2}$, Andrzej Dziembowski ${ }^{1,3}$, Leszek Lipinski1 and Adam Sobczak ${ }^{1,3 *}$

${ }^{1}$ Institute of Biochemistry and Biophysics, Polish Academy of Sciences, Warsaw, Poland, ${ }^{2}$ Institute of Organic Chemistry, Polish Academy of Sciences, Warsaw, Poland, ${ }^{3}$ Institute of Genetics and Biotechnology, Faculty of Biology, University of Warsaw, Warsaw, Poland

OPEN ACCESS

Edited by:

Dimitrios Georgios Karpouzas, University of Thessaly, Greece

Reviewed by:

Esperanza Romero Taboada, Consejo Superior de Investigaciones

Cientificas (CSIC), Spain

Michalis D. Omirou,

Agricultural Research Institute, Cyprus

Chiara Perruchon,

University of Thessaly, Greece

*Correspondence:

Adam Sobczak

adams@ibb.waw.pl

Specialty section:

This article was submitted to

Systems Microbiology,

a section of the journal

Frontiers in Microbiology

Received: 04 May 2017 Accepted: 13 September 2017

Published: 07 November 2017

Citation:

Furmanczyk EM, Kaminski MA, Spolnik G, Sojka M, Danikiewicz W,

Dziembowski A, Lipinski $L$ and Sobczak A (2017) Isolation and Characterization of Pseudomonas spp. Strains That Efficiently Decompose Sodium Dodecyl Sulfate.

Front. Microbiol. 8:1872. doi: 10.3389/fmicb.2017.01872
Due to their particular properties, detergents are widely used in household cleaning products, cosmetics, pharmaceuticals, and in agriculture as adjuvants tailoring the features of pesticides or other crop protection agents. The continuously growing use of these various products means that water soluble detergents have become one of the most problematic groups of pollutants for the aquatic and terrestrial environments. Thus it is important to identify bacteria having the ability to survive in the presence of large quantities of detergent and efficiently decompose it to non-surface active compounds. In this study, we used peaty soil sampled from a surface flow constructed wetland in a wastewater treatment plant to isolate bacteria that degrade sodium dodecyl sulfate (SDS). We identified and initially characterized 36 Pseudomonas spp. strains that varied significantly in their ability to use SDS as their sole carbon source. Five isolates having the closest taxonomic relationship to the Pseudomonas jessenii subgroup appeared to be the most efficient SDS degraders, decomposing from 80 to $100 \%$ of the SDS present in an initial concentration $1 \mathrm{~g} / \mathrm{L}$ in less than $24 \mathrm{~h}$. These isolates exhibited significant differences in degree of SDS degradation, their resistance to high detergent concentration (ranging from $2.5 \mathrm{~g} / \mathrm{L}$ up to $10 \mathrm{~g} / \mathrm{L}$ or higher), and in chemotaxis toward SDS on a plate test. Mass spectrometry revealed several SDS degradation products, 1-dodecanol being dominant; however, traces of dodecanal, 2-dodecanol, and 3-dodecanol were also observed, but no dodecanoic acid. Native polyacrylamide gel electrophoresis zymography revealed that all of the selected isolates possessed alkylsulfatase-like activity. Three isolates, AP3_10, AP3_20, and AP3_22, showed a single band on native PAGE zymography, that could be the result of alkylsulfatase activity, whereas for isolates AP3_16 and AP3_19 two bands were observed. Moreover, the AP3_22 strain exhibited a band in presence of both glucose and SDS, whereas in other isolates, the band was visible solely in presence of detergent in the culture medium. This suggests that these microorganisms isolated from peaty soil exhibit exceptional capabilities to survive in, and break down SDS, and they should be considered as a valuable source of biotechnological tools for future bioremediation and industrial applications.

Keywords: biodegradation, xenobiotics, sodium dodecyl sulfate, alkyl sulfatase, Pseudomonas sp., surface flow constructed wetland, SPME-GC-MS, biodiversity 


\section{INTRODUCTION}

Surfactants are amphiphilic compounds with both hydrophilic and hydrophobic parts. This allows them to accumulate at the interfaces between air and water, or water and oil and lower the surface tension. According to their charge in aqueous solutions, surfactants can be grouped into anionic, non-ionic, cationic, or amphoteric classes (Im et al., 2008). The low price and beneficial properties of anionic surfactants make them popular additives to a wide range of products like: cosmetics, pharmaceuticals, household and industrial cleaning products, and in agriculture as adjuvants improving spraying properties and pesticide penetration.

The extensive application of surfactants in household and agricultural products results in an accumulation of these compounds in aquatic and terrestrial environments, giving rise to toxic effects on living organisms. Anionic detergents such as SDS are known to have bacteriostatic or even bactericidal properties and inhibit the growth of some nitrogen-fixing cyanobacteria, algae, crustaceans (Lechuga et al., 2016), and also fishes (Sandbacka et al., 2000). The features underlying their accumulation in living organisms and toxicity are the amphoteric properties of these detergents, which promote interactions with intracellular components by means of both electrostatic (by the negatively charged head) or hydrophobic (by the hydrophobic part) forces (Cserhati et al., 2002).

Problems caused by large amounts of surfactants are clearly visible in sewage treatment plants, where detergents present in the wastewater negatively influence the physicochemical and biological processes employed in water purification. On the physicochemical level, the decreased surface tension of the liquid causes a deterioration in the flocculation and sedimentation of small particles by stabilizing their colloidal suspension. On the biological level, anionic surfactants affect the functioning of the sludge microbial consortium on several levels, having a negative effect on its biodiversity and a pivotal role in the decomposition of numerous xenobiotics. Among the numerous possible mechanisms underlying the negative influence of anionic surfactants on living organisms, several have already been determined (Ivanković and Hrenović, 2010): (I) absorption of detergents at the surface of activated sludge flocs, triggering bacterial cell lysis; (II) interactions with proteins, causing disruption and conformational changes to their tertiary structure; and (III) binding at enzymes' active sites or substrate-binding pockets, influencing chemical reactions. In consequence, surfaceactive xenobiotics decrease the metabolism of microorganisms, which lose the activity of certain groups of enzymes, and thus change the degradation profile of some compounds (e.g., carbohydrates) (Eerlingen et al., 1994). Overall, high surfactant concentrations in wastewater decrease biodiversity and the metabolic processes conducted within active sludge consortia, making the whole water purification process inefficient and costly (Zangeneh et al., 2014).

Despite their known toxicity, the use of anionic detergents is often proposed for the bioremediation of hydrocarboncontaminated soils or water, due to their ability to increase the water solubility and bioavailability of many hydrophobic xenobiotics. In this context, SDS is one of the most popular detergents proposed for soil bioremediation (Yu et al., 2007; Zhou and Zhu, 2008; Moldes et al., 2013). However, bacterially augmented bioremediation in the presence of SDS is not an easy process, requiring the use of several types of microorganisms: (a) xenobiotic decomposers applied in the first step of bioremediation, resistant to the presence of anionic detergent, and (b) efficient detergent degraders used in the second step.

There are various reports describing the isolation of bacteria having the capacity to degrade surfactants, including a wide variety of Pseudomonas strains (Klebensberger et al., 2006; Chaturvedi and Kumar, 2011a; Yeldho et al., 2011; John et al., 2015), Klebsiella oxytoca (Shukor et al., 2009; Masdor et al., 2015), Enterobacter sp. strain NENI-13 (Rahman et al., 2016), and finally microbial consortia composed of Acinetobacter calcoaceticus and Pantoea agglomerans (Abboud et al., 2007). However, these microorganisms were selected from environments highly contaminated solely with detergents with no other xenobiotics present.

In this study, we sampled peaty soil coming from the root zone of a surface flow constructed wetland of a wastewater treatment plant operated by a pesticide packing company, having excellent sewage purification properties. As detergents are widely used as adjuvants, tailoring the properties of crop protection products to the end-user's needs, we assumed that microorganisms inhabiting this soil sample should have the ability to efficiently decompose detergents, combined with high resistance to such toxic xenobiotics. We found it intriguing to compare the microbial biodiversity of the analyzed peaty soil sample and the taxonomy of the isolated microorganisms having the desired metabolic properties. Such a comparison could be helpful in elucidating which culturable taxonomic groups could be considered as responsible for detergent decomposition in the soil sampled from the root zone. Finally, we provided initial biochemical characterization of the most promising isolates, those that exhibited desirable features, such as efficient SDS decomposition combined with resistance to substantial detergent concentrations.

\section{MATERIALS AND METHODS}

\section{Soil Sample Collection}

A soil sample was collected from a subsurface flow constructed wetland of a wastewater treatment plant operated by Agropak s.j. (Jaworzno City, Poland), a Polish pesticide producer, where large amounts of peaty soil are used as a biologically active filter. The samples were taken from a depth of 5-30 cm at four independent sites (with $50 \mathrm{~cm}$ distances between) forming a parallel line $5 \mathrm{~m}$ from the basin collecting the pesticide-contaminated water. The subsamples were combined obtaining approximately $3 \mathrm{~kg}$ of soil which were thoroughly mixed to homogenize and sieved with $1 / 4$ " and 1/16" sieves. For DNA isolation, homogenized soil was subsampled in and frozen with dry ice in the field, then stored at $-80^{\circ} \mathrm{C}$. For bacterial isolation, soil samples were placed in plastic bags and stored at $8^{\circ} \mathrm{C}$. 


\section{Media Preparation}

Lysogeny broth (LB) medium (per liter: $10 \mathrm{~g}$ tryptone; $5 \mathrm{~g}$ yeast extract; $5 \mathrm{~g} \mathrm{NaCl}$ ) (Sambrook and Russel, 2001), 10 times diluted LB medium (0.1X LB), basal medium [per liter: $3.5 \mathrm{~g} \mathrm{KH}_{2} \mathrm{PO}_{4}$;

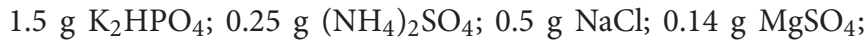
$0.15 \mathrm{~g} \mathrm{MgCl}_{2} .6 \mathrm{H}_{2} \mathrm{O}$ ] (Shahbazi et al., 2013), or minimal medium [per liter: $0.5 \mathrm{~g} \mathrm{Na}_{2} \mathrm{HPO}_{4} ; 0.5 \mathrm{~g} \mathrm{KH}_{2} \mathrm{PO}_{4} ; 0.25 \mathrm{~g}\left(\mathrm{NH}_{4}\right)_{2} \mathrm{SO}_{4}$ ] were used during this study. The soil extract was prepared by autoclaving of $500 \mathrm{~g}$ of air-dried garden soil mixed with $1 \mathrm{~L}$ of tap water for $1 \mathrm{~h}$ at $121^{\circ} \mathrm{C}$. Solid particles were centrifuged for at least $10 \mathrm{~min}$, and the resulting supernatant was used for further experiments. Solid media were obtained by the addition of $1.5 \%$ agar. SDS $(1 \mathrm{~g} / \mathrm{L}$ or $2 \mathrm{~g} / \mathrm{L})$ was used as a carbon source in the minimal media. The 20\% (w/v) SDS (Sigma-Aldrich) and 20\% $(\mathrm{w} / \mathrm{v})$ glucose $(\mathrm{POCH})$ stock solutions were prepared in ultrapure water and sterilized by filtration.

\section{Isolation of SDS-Degrading Bacteria}

Ten gram of the collected soil stored at $8^{\circ} \mathrm{C}$ was placed into the sterile container of a Waring blender, and $100 \mathrm{~mL}$ of $0.9 \%$ $\mathrm{NaCl}$ was added. The sample was homogenized by three blending cycles at maximum speed for $1 \mathrm{~min}$, with intermittent cooling on ice for $1 \mathrm{~min}$. After $5 \mathrm{~min}$ of sedimentation, the liquid fraction was transferred into a sterile beaker. Another $100 \mathrm{~mL}$ of $0.9 \% \mathrm{NaCl}$ was then added to the soil sludge, and the whole procedure was repeated three times in total. All the fractions were pooled together and centrifuged at 5,000 $\mathrm{g}$ for $10 \mathrm{~min}$ at $4^{\circ} \mathrm{C}$. Several dilutions of the obtained pellet were plated on solid soil extracts plates. After 7 days of incubation at $23^{\circ} \mathrm{C}$, colonies with unique morphologies were transferred into 96-well plates containing soil extract supplemented with $15 \%$ glycerol and stored at $-80^{\circ} \mathrm{C}$.

Isolated microorganisms were replicated on solid basal medium plates with SDS $(2 \mathrm{~g} / \mathrm{L})$ as the carbon source. In the basal medium SDS precipitates make this medium suitable for observations, as a clear halo surrounding growing bacterial colonies forms, indicating detergent degradation. To shorten the time of colony growth and halo formation, plates were incubated at an increased temperature of $30^{\circ} \mathrm{C}$ for 3-4 days. Isolates with clear halos around the colonies were considered to have SDS degrading features. They were then verified to be pure by two independent streaking passages on the same medium, and finally selected for further SDS biodegradation study.

\section{Preliminary SDS Biodegradation Test: The Colorimetric Assay}

The selected isolates were pre-cultured overnight in liquid $0.1 \mathrm{X}$ LB medium unsupplemented with detergent at $30^{\circ} \mathrm{C}$ with orbital agitation (140 rpm). Minimal medium supplemented with $0.1 \%$ SDS $(1 \mathrm{~g} / \mathrm{L})$ was inoculated to $\mathrm{OD}_{600}=0.05-0.15$ with the overnight culture, which had been washed with minimal medium without any carbon source. The detergent concentration was measured by colorimetric assay at $0,2,4,6,8$, and $24 \mathrm{~h}$ after the beginning of the experiment. The minimal medium was used in liquid cultures for colorimetric assays because there was no SDS precipitation observed under this condition.
The SDS concentration was determined in a 96-well plate using Stains-All reagent (Sigma-Aldrich) as described elsewhere (Rusconi et al., 2001) with minor modifications. Stains-All stock solution $(1 \mathrm{mg} / \mathrm{mL})$ was prepared in isopropanol:water (50:50). The working solution (WS) consisted of $1 \mathrm{~mL}$ of the stock diluted in $18 \mathrm{~mL}$ of water and $1 \mathrm{~mL}$ of formamide. Samples from each time points were diluted 10 times, $8 \mu \mathrm{L}$ of diluted sample were dispensed into the well, supplemented with $100 \mu \mathrm{L}$ of water and $100 \mu \mathrm{L}$ of the Stains-All working solution, and finally the absorbance (at $438 \mathrm{~nm}$ ) was measured after 10 min of incubation at RT. The measurements were carried out in triplicate. Results of colorimetric assay were confirmed also by mass spectrometry.

\section{Isolation and Purification of Soil Total DNA}

The metagenomic DNA isolation was done in triplicate. Five grams of soil sample was resuspended in $4 \mathrm{~mL}$ Zhou buffer (Zhou et al., 1996); $2 \mathrm{~g}$ of $0.5 \mathrm{~mm}$ zirconia/silica beads were added, and the mixture was vortexed for $15 \mathrm{~s}$ at maximum rpm. After centrifugation, the supernatant was transferred to a new tube and $4 \mathrm{~mL}$ of fresh Zhou buffer was added to the soil. The procedure was repeated two times, and the supernatants were combined together into fraction A. Six mL of Zhou buffer was added to the remaining soil sediment and mixed (fraction B). One hundred $\mu \mathrm{L}$ of lysozyme $(100 \mathrm{mg} / \mathrm{mL}), 34 \mu \mathrm{L}$ of achromopeptidase $(100 \mathrm{kU} / \mathrm{mL})$, and $25 \mu \mathrm{L}$ RNase A $(10 \mathrm{mg} / \mathrm{mL})$ were added to each fraction, and they were incubated for $1 \mathrm{~h}$ in a water bath at $37^{\circ} \mathrm{C}$. After this time, $25 \mu \mathrm{L}$ of proteinase $\mathrm{K}(40 \mathrm{mg} / \mathrm{mL})$ was added, and the fractions were incubated for $30 \mathrm{~min}$ at $37^{\circ} \mathrm{C}$. Next $0.75 \mathrm{~mL}$ of $20 \%$ SDS was added, and the suspension was incubated for $2 \mathrm{~h}$ in a water bath at $55^{\circ} \mathrm{C}$ with mixing by inversion at $15 \mathrm{~min}$ intervals. After this time, each sample was chilled on ice for $2 \mathrm{~min}$, centrifuged ( $20 \mathrm{~min}$, RT, 8,000 rpm), and the resulting supernatant was extracted twice with equal volumes of chloroform. The DNA was then precipitated overnight in the presence of $10 \%$ PEG 8000 at $4^{\circ} \mathrm{C}$. The DNA pellet from each fraction was centrifuged $\left(45 \mathrm{~min}, 4^{\circ} \mathrm{C}, 10,000 \mathrm{~g}\right)$, washed twice with $70 \%$ ethanol and resuspended in $200 \mu \mathrm{L}$ of water.

The whole community DNA was purified using Q Sepharose (Sigma-Aldrich). Briefly, the resin was first washed with TE buffer, and then $200 \mu \mathrm{L}$ samples of isolated DNA from each fraction were combined with $100 \mu \mathrm{L}$ of the resin. The solution was mixed for $15 \mathrm{~min}$ by inversion at RT. After a short centrifugation ( $15 \mathrm{~s}, 800 \mathrm{rpm})$, the supernatants were transferred to new tubes. The procedure was repeated once for DNA from fractions A and six times for DNA from fractions B. The fractions were combined in an equal concentration ratio, and $100 \mu \mathrm{L}$ of this solution was purified using AMPureXP (1:1 ratio) (Beckman Coulter) and resuspended in $50 \mu \mathrm{L}$ of water.

\section{Metagenomic Library Preparation and Sequencing}

Two types of libraries were constructed using the amplified V3-V4 16S rRNA region (464 bp): the first one, AP3MET, representing the metagenomic diversity of the soil sample; and the second, AP3BAC, representing the biodiversity of the 
preselected SDS-degrading bacterial isolates. For the AP3MET library, $100 \mathrm{ng}$ of the purified metagenomic DNA was used as a template. For the AP3BAC library, the amplicons for individual isolates were amplified separately using colony PCR. A single colony of each selected isolate, cultured on basal medium with SDS as a sole carbon source, was resuspended in $20 \mu \mathrm{L}$ of PCR lysis solution ( $50 \mathrm{mM} \mathrm{NaOH}$; $0.25 \%$ SDS) and boiled at $99^{\circ} \mathrm{C}$ for $10 \mathrm{~min}$. The samples were then placed on ice, and $180 \mu \mathrm{L}$ of cold sterile water was added. These solutions were used as templates for PCR. In both cases, PCR was performed in a TProfessional Basic Thermocycler (Biometra), using Phusion polymerase (0.02 U/ $\mu$ l, Thermo; supplied with $1 \mathrm{x}$ HF-buffer), $0.2 \mathrm{mM}$ dNTP mixture, and primers specific to V3-V4 region of $16 \mathrm{~S}$ rRNA gene S-D-Bact0341-b-S-17 (CCTACGGGNGGCWGCAG) and S-D-Bact-0785a-A-21 (GACTACHVGGGTATCTAATCC) (Klindworth et al., 2013), - $0.4 \mu \mathrm{M}$ each, under the following conditions: one cycle at $96^{\circ} \mathrm{C}$ for $2 \mathrm{~min}, 21$ or 25 cycles (for bacterial or environmental DNA) at $96^{\circ} \mathrm{C}$ for $30 \mathrm{~s}, 54^{\circ} \mathrm{C}$ for $50 \mathrm{~s}$, and $72^{\circ} \mathrm{C}$ for $20 \mathrm{~s}$ with final extension at $72^{\circ} \mathrm{C}$ for $5 \mathrm{~min}$. The amplified DNA fragments were purified using AMPureXP beads (1:1 ratio) according to the manufacturer's instructions. The products from each of the preselected SDS-degrading isolates (for the AP3BAC library) were purified separately and then pooled together in equal molar ratios. Approximately $250 \mathrm{ng}$ of purified PCR product was used for each library preparation using the KAPA HTP Library Preparation Kit for Illumina platforms according to the manufacturer's protocol, except that the final library amplification was omitted. The libraries were verified using a 2100 Bioanalyzer (Agilent) High-Sensitivity DNA assay and a KAPA Library Quantification Kit for Illumina. Pair-end sequencing was performed using an Illumina MiSeq (MiSeq Reagent Kit v3, 600 cycles) with a read length of $2 \times 300 \mathrm{bp}$.

\section{Bioinformatic Analysis of High-Throughput Amplicon Data}

The obtained reads for each library were filtered to quality scores (Q30) and then merged using FLASH software (Magoč and Salzberg, 2011). The adaptor and primer sequences were deleted using the Cutadapt script (Martin, 2011). Merged sequences with at least $400 \mathrm{bp}$ were used in analysis, with various scripts implemented in QIIME (v 1.9) (Caporaso et al., 2010). Firstly, they were clustered into operational taxonomic units (OTU) with an identity threshold of 97\% using ULUST (Edgar, 2010). Representative sequences for each OTU were used to assign taxonomy using the RDP classifier (Wang et al., 2007) against the SILVA (Quast et al., 2013) database (release 128) and to build an OTU table. Amplicon sequences were deposited in the NCBI's SRA database (BioProject PRJNA361553).

\section{Bacteria Identification via 16S rRNA Gene Analysis and Phylogenetic Tree Construction}

The 16S rRNA gene (approximately 1,500 bp) of the top five degraders was amplified by colony PCR using the following universal primer pair: 27F (AGAGTTTGATCCTGGCTCAG) and 1492R (GGTTACCTTGTTACGACTT) (Lane, 1991). A single colony of each selected isolate grown on basal minimal medium with SDS as a carbon source was resuspended in $20 \mu \mathrm{L}$ of PCR lysis solution (50 mM NaOH; 0.25\% SDS) and boiled at $99^{\circ} \mathrm{C}$ for $10 \mathrm{~min}$. The samples were then placed on ice, and $180 \mu \mathrm{L}$ of cold sterile water was added. These solutions were used as templates. The PCR was performed in $50 \mu \mathrm{L}$ using Phusion High-Fidelity DNA Polymerase (Thermo; supplied HF Buffer and other components as mentioned previously). The PCR involved: one cycle at $99^{\circ} \mathrm{C}$ for $5 \mathrm{~min} ; 10$ cycles at $99^{\circ} \mathrm{C}$ for $30 \mathrm{~s}, 60^{\circ} \mathrm{C}$ for $30 \mathrm{~s}$, and $72^{\circ} \mathrm{C}$ for $45 \mathrm{~s}$; and 20 cycles at $99^{\circ} \mathrm{C}$ for $30 \mathrm{~s}, 50^{\circ} \mathrm{C}$ for $30 \mathrm{~s}$, and $72^{\circ} \mathrm{C}$ for $45 \mathrm{~s}$ with final extension at $72^{\circ} \mathrm{C}$ for $5 \mathrm{~min}$. The PCR products (approximately 1,500 bp) of $16 \mathrm{~S}$ rRNA genes were purified using AMPureXP with a 0.8:1 ratio, then cloned into a $\mathrm{pCR}^{\mathrm{TM}}$ Blunt II-TOPO ${ }^{\circledR}$ vector (Thermo Fisher) according to the manufacturer's protocol, and transformed to Escherichia coli (Sambrook and Russel, 2001). The plasmids were isolated using a Plasmid Mini kit (A\&A Biotechnology) and the inserts were sequenced with Sanger using universal M13 Forward (GTAAAACGACGGCCAG) and M13 Reverse (CAGGAAACAGCTATGAC) primers (Thermo Fisher). 16S rRNA partial gene sequences were deposited at the NCBI (GenBank accession numbers: KY462011-KY462014 and MF554631). The sequences were compared to the EzBioCloud database (Yoon et al., 2017).

The sequences were aligned to each other using ClustalW (Larkin et al., 2007). 16S rRNA gene sequences of the five selected SDS-degrading isolates and 27 representative sequences of reference type strains from the NCBI database were used to construct a phylogenetic tree. Multiple sequence alignment to identify the maximum identical gene fragment was carried out using ClustalW (Larkin et al., 2007). A maximum likelihood tree was constructed in MEGA 6.0 (Tamura et al., 2013) with 1,000 bootstrap replicates using Tamura-Nei model and default settings.

\section{Characterization of the SDS-Degrading Ability by the Selected Isolates Effect of SDS Concentration on Bacterial Growth}

The selected isolates were pre-cultured overnight in LB medium as mentioned before, washed two times with minimal medium without any carbon source, and then diluted to $\mathrm{OD}_{600}=0.15 \mathrm{in}$ minimal medium with different SDS concentrations $(0.5-50 \mathrm{~g} / \mathrm{L})$ as the sole carbon source. The isolates were cultured in triplicate in 48-deep well plates. The optical density of the cultures was monitored after $24 \mathrm{~h}$ of incubation. Statistical analysis and interpretation of obtained data was made using the $\mathrm{R}$ package version 3.5.0. The Kruskal-Wallis with the Dunn's post hoc tests were used to test differences between initial and final optical density of cultures, with significance set at a probability smaller than 0.05 .

\section{Drop Plate Assay for Chemotaxis}

Overnight LB-pre-cultures of the selected isolates were used to inoculate fresh $50 \mathrm{~mL}$ LB medium (1:50, v/v). After $2 \mathrm{~h}$ of incubation at $30^{\circ} \mathrm{C}$, cells were harvested by centrifugation at $8,000 \mathrm{rpm}$ for $15 \mathrm{~min}$, washed twice with $0.9 \% \mathrm{NaCl}$, resuspended 
to a final concentration $\mathrm{OD}_{600}=0.1$ in minimal medium containing $0.45 \%$ bacto agar and poured into $30 \mathrm{~mm}$ petri plates. Next five $\mu \mathrm{L}$ of $20 \%$ SDS or $20 \%$ glucose were dropped into the center of the petri plate, and the chemotactic response was observed after $8 \mathrm{~h}$ of incubation at $30^{\circ} \mathrm{C}$.

\section{LC-MS/MS Quantitation of SDS}

For chemical analysis of SDS degradation, the selected isolates were pre-cultured in $\mathrm{LB}$ medium at $30^{\circ} \mathrm{C}$ with agitation (140 rpm). The cultures were then diluted to $\mathrm{OD}_{600} 0.1-0.15$ in $50 \mathrm{~mL}$ of minimal medium supplemented with $0.1 \%$ SDS as the sole carbon source and cultured as mentioned above. After $24 \mathrm{~h}$ of growth, cells were centrifuged at 10,000 rpm for $15 \mathrm{~min}$, and the concentration of SDS was measured using a Prominence LC-20 HPLC (Shimadzu) coupled with a 4000 QTRAP tandem mass spectrometer (SCIEX) equipped with an electrospray ion source. The separation was performed using a $4.6 \mathrm{~mm} \times 250 \mathrm{~mm}$ XDB-C8 $(5 \mu \mathrm{m})$ column (Agilent). A gradient flow was used for all measurements. Solvent A consisted of $5 \mathrm{mM}$ ammonium acetate in water, while the solvent B was acetonitrile (both HPLC grade). The gradient ran from 50 to $100 \%$ of solvent B in $5 \mathrm{~min}, 100 \%$ of solvent B was maintained for $2 \mathrm{~min}$, and was then returned to the initial conditions. For quantitative analysis, multiple reaction monitoring (MRM) experiments were carried out in negative ion mode. The $\mathrm{m} / \mathrm{z}$ $265 / 80$ and 265/97 precursor/product ion pairs were used as quantitative and confirmative ions, respectively. Zero air was used as the nebulizer gas, and nitrogen as the curtain gas. The tip voltage was kept at $4.5 \mathrm{kV}$. The compound dependent declustering potential and collision energy values were set, and the dwell time was $20 \mathrm{~ms}$. Standard solutions were prepared by dissolving the SDS standard in water in a range from 30 to $600 \mathrm{ng} / \mathrm{mL}$. All supernatant samples were diluted by 50 times twice, to reach the optimum concentration for the applied method.

\section{SPME-GC-MS Analysis}

The analysis of potential SDS metabolites in supernatants was performed using the solid-phase microextraction technique by suspending a $100 \mu \mathrm{m}, 24$ ga PDMS fiber (Supelco) above $2 \mathrm{~mL}$ of the supernatant sample placed in a $20 \mathrm{~mL}$ closed headspace vial. The sampling process was carried out for $30 \mathrm{~min}$ for each sample, and immediately afterward the fiber was inserted into the injector, and heated to $260^{\circ} \mathrm{C}$ to start the analysis. GC-MS analyses were performed on an Agilent 7890A gas chromatograph coupled with an Agilent 5975C mass spectrometer equipped with an EI (electron ionization) source and a single quadrupole mass analyser. Separation was performed on an Agilent HP-5ms column $(30 \mathrm{~m} \times 250 \mu \mathrm{m} \times 0.25 \mu \mathrm{m})$. The carrier gas was helium, and the flow rate was $1 \mathrm{~mL} / \mathrm{min}$. The temperature program was $100^{\circ} \mathrm{C}$ for $2 \mathrm{~min}$, then $15^{\circ} / \mathrm{min}$ to $300^{\circ} \mathrm{C}$, and $300^{\circ} \mathrm{C}$ for $10 \mathrm{~min}$.

\section{Crude Cell Extracts Preparation for Native PAGE Zymography}

Bacterial cells were precultured overnight in LB medium, diluted to $\mathrm{OD}_{600}=0.15$ in $100 \mathrm{ml}$ of minimal medium supplemented with $1 \mathrm{~g} / \mathrm{L}$ SDS or glucose as the carbon source, and incubated

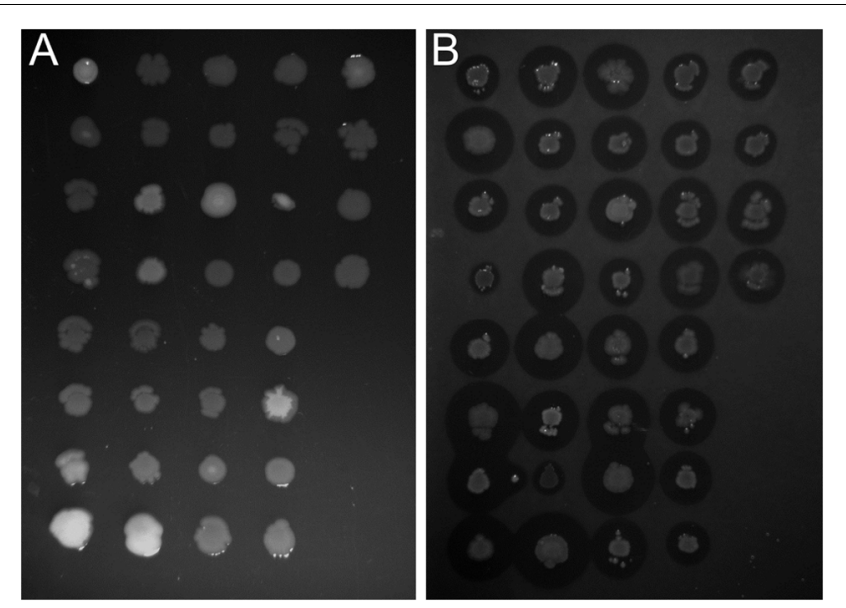

FIGURE 1 | Identification of bacteria potentially degrading sodium dodecyl sulfate (SDS). Comparison of growth profile of selected strains cultured on solidified 0.1X LB (A) or basal medium supplemented with $0.2 \%$ SDS (B). Differences in clear zone diameter are observed for each strain cultured on SDS-containing medium indicate a variety of degree of detergent metabolism.

for $20 \mathrm{~h}$ at $30^{\circ} \mathrm{C}$. Cells were harvested by centrifugation at $10,000 \mathrm{~g}$ for $15 \mathrm{~min}$ at RT. Cell pellets were resuspended in lysis buffer (50 mM HEPES, pH 7.5, $300 \mathrm{mM} \mathrm{NaCl}, 20 \mathrm{mM}$ imidazole, $50 \mu \mathrm{M}$ PMSF, $10 \mathrm{mM} \beta$-mercaptoethanol, $0.1 \%$ Tween $20,10 \%$ glycerol, and lysozyme) and disrupted by sonication in a Diagenode sonication system in a cooled water bath $\left(4^{\circ} \mathrm{C}\right)$ at high power $(300 \mathrm{~W})$ for 30 cycles of $30 \mathrm{~s}$ on and $30 \mathrm{~s}$ off. Cell debris was removed by centrifugation at $14,000 \mathrm{~g}$ for $30 \mathrm{~min}$ at $4^{\circ} \mathrm{C}$ and the supernatants were stored at $-20^{\circ} \mathrm{C}$.

To determine the sulfatase activity, the crude cell extracts ( $60 \mu \mathrm{g}$ of protein) were separated using $8 \%$ native polyacrylamide gel (Sambrook and Russel, 2001). The electrophoresis was carried out at $100 \mathrm{~V}$ at $4^{\circ} \mathrm{C}$ in $0.378 \mathrm{M}$ Tris-glycine buffer ( $\mathrm{pH}$ 8.3). After washing in ultrapure water, the gel was incubated in a developing solution containing $20 \mathrm{mM}$ SDS in $0.1 \mathrm{M}$ Tris- $\mathrm{Cl}(\mathrm{pH} \mathrm{7.5)}$ at $30^{\circ} \mathrm{C}$. Active alkyl sulfatases was visualized by the formation of white bands of insoluble alcohol.

\section{RESULTS}

\section{Isolation of SDS-Degrading Microorganisms}

In this study we used the peaty soil from biological wastewater treatment plant regularly exposed to pesticides and detergents as a source of unknown SDS-degrading microorganisms. The isolation procedure based on the ability to grow on the solid soil extract under laboratory conditions resulted in the selection of 238 morphologically distinctive colonies. Their ability to survive and decompose SDS was assessed on solid basal medium supplemented with SDS (2 $\mathrm{g} / \mathrm{L})$ as the sole carbon source. For 36 isolates, a clear halo surrounding the colony was observed, which was interpreted as the ability to decompose SDS (compare Figures 1A,B). This assumption was further 

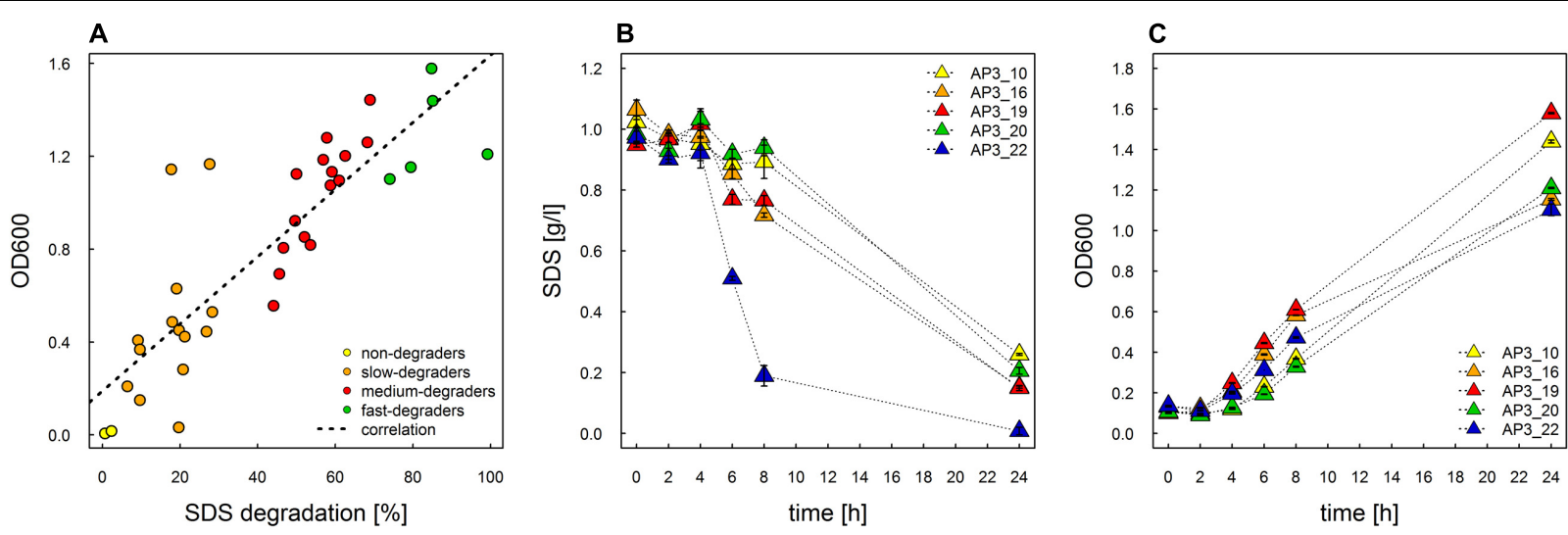

FIGURE 2 | Study of SDS degradation of selected isolates. (A) Correlation of growth rate and SDS degradation (decrease in substrate concentration [\%]) after $24 \mathrm{~h}$ of incubation plotted for the 36 selected strains. The dotted line represents correlation. (B) Time course study of degree of SDS degradation of the top five selected strains. (C) Time course study of growth rate for the five most effective degraders selected during the experiment. The values are means of the three replicates, and the error bars indicate the standard deviations.

confirmed in liquid cultures by a SDS-measuring colorimetric assay (see Figure 2, and for details Supplementary Table S1). Two isolates did not adapt to liquid culture, showing minor growth with no SDS decomposition observed after $24 \mathrm{~h}$ of incubation. In the remaining 34 cases, degradation of SDS was observed as a decrease from the initial detergent concentration in liquid culture measured in percent ranged from 6.4 to $99.2 \%$ (Figure 2A). Based on the degree of SDS degradation, the isolates were arranged into four metabolic classes reflecting their SDSdegradation ability: non-degraders (2 isolates), slow-degraders (14 isolates with an SDS degree of degradation below 30\%), medium degraders (15 isolates with a degree of SDS degradation between 31 and $70 \%$ ), and fast degraders (5 isolates with the degree of SDS degradation exceeding 70\%). The most promising isolate, AP3_22, utilized approximately 50 and $81 \%$ of SDS within 6 and $8 \mathrm{~h}$ of the experiment, respectively (Figure 2B). After $24 \mathrm{~h}$, the fast degrading isolates were able to degrade: $74.1 \%-$ AP3_10; 84.6\% - AP3_16; 85.1\% - AP3_19, 79.4\% - AP3_20, and $99.2 \%$ - AP3_22 of SDS (from the initial $1 \mathrm{~g} / \mathrm{L}$ ). This experiment showed a strong positive correlation (correlation coefficient $r=0.86$ ) between the degree of SDS degradation and the optical density of the isolates liquid cultures (Figure 2A). Analysis of $\mathrm{OD}_{600}$ changes for isolates cultured in liquid media revealed differences in bacterial behavior in response to detergent exposure. For 23 isolates, a decrease in optical density was observed during the lag phase, usually lasting $2 \mathrm{~h}$, which could be interpreted as an adaptation phase (Supplementary Table S1). In contrast, another 11 isolates were characterized with a very short lag phase and continuous culture growth during the whole experiment. From the fast degraders group isolate AP3_19 was able to actively grow almost from the beginning of the experiment having the shortest adaptation phase (Figure 2C). However, in case of this isolate the most efficient growth did not translate to the highest degree of SDS degradation (Figure 2B), as the AP3_19 isolate turned to be second the most efficient degrader. Isolates AP3_10 and AP3_20 showed slower initial growth, nonetheless, it did not affect their final optical density (Figure 2C). Isolates
AP3_16 and AP3_22 were characterized with very similar growth patterns (with very short lag phase) but they differ significantly in SDS degradation (compare Figures 2B,C).

\section{Biodiversity of the Soil Sample and Taxonomic Analysis of the Isolated SDS-Degrading Bacteria}

\section{Biodiversity of the Soil Sample}

Next we analyzed the taxonomy of the isolated culturable SDS-degrading microorganisms in context of the taxonomic biodiversity of soil sample of their origin. For the taxonomic biodiversity of soil sample, whole microbial community DNA was extracted, and amplicons of the V3-V4 region of the 16S rRNA gene were sequenced on an Illumina MiSeq platform, resulting in 252,124 paired reads. After quality filtering, read merging, adaptor and primer trimming, and length filtering, 206,771 sequences were obtained and used in a biodiversity analysis performed with QIIME.

A total of $99.94 \%$ of the sequences were assigned to various taxonomic levels inside domain Bacteria, grouped in 45 different phyla, while $0.06 \%$ sequences remained unclassified.

The most abundant 12 phyla ( $>1 \%$ sequences) comprised $94.02 \%$ of the AP3 community (Figure 3A), within which $33.52 \%$ of the sequences belonged to the Proteobacteria phylum. The second most numerous phylum was Parcubacteria (16.04\%), also known as $O D 1$, gathering non-culturable bacteria widespread in various anoxic environments (Nelson and Stegen, 2015). Other common phyla identified in the AP3 soil sample were Acidobacteria (10.70\%), Bacteroidetes (8.04\%), and Verrucomicrobia (6.18\%). Planctomycetes, Chloroflexi, Chlamydiae, and Gemmatimonadetes were less prevalent phyla.

Further analysis showed that the Proteobacteria phylum was mainly composed of four classes: Alphaproteobacteria (11.07\%) with Rhizobiales (5.95\%) as the main order, Betaproteobacteria (8.85\%) with Nitrosomonadales $(5.36 \%)$ as the main order, Gammaproteobacteria (7.26\%) with Methylococcales (3.04\%) 


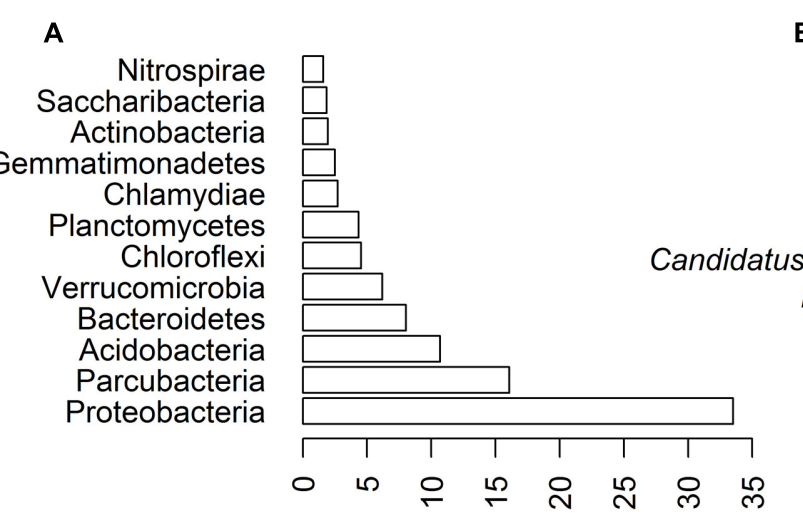

B

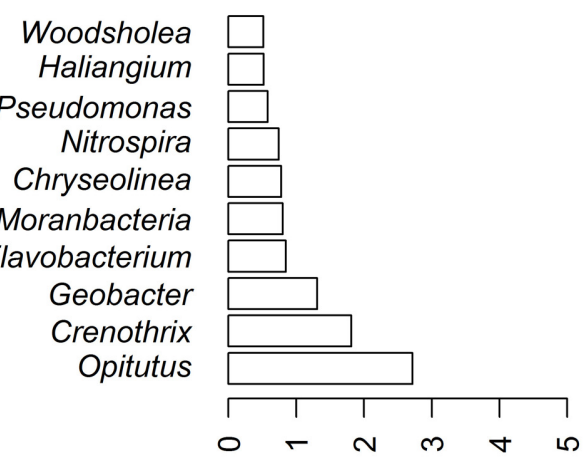

FIGURE 3 | Biodiversity of AP3 soil sample based on bioinformatics analysis of deep sequencing of AP3MET library. Community composition at different taxonomic ranks: (A) phylum level. (B) 10 most represented genera in the soil sample.

as the main order, and Deltaproteobacteria (6.09\%) with Myxococcales $(2.01 \%)$ as the main order. Detailed taxonomic representation at the aforementioned taxonomic levels is presented in the Supplementary Figure S1. Fifty-three bacterial genera were present in at least $0.1 \%$ relative abundance of sequences. Opitutus (2.72\%) was the most abundant genus. Also Crenothrix (1.81\%) and Geobacter (1.31\%), belonging to the Proteobacteria phylum, were among the most abundant genera representing the bacterial community. The 10 most represented genera are shown on Figure 3B.

\section{Taxonomic Analysis of Isolated Bacteria}

In next step, taxonomic classification of the 36 promising isolates was confirmed by sequencing of the amplicons comprising V3-V4 region of the $16 \mathrm{~S}$ rRNA gene. From 95,564 paired reads for the bacterial V3-V4 library (AP3BAC) after quality filtering (Q30), read merging, adaptor and primer trimming, and length filtering, 60,063 sequences were employed in the biodiversity analysis with QIIME. A total of $97.45 \%$ of the sequences were assigned to the Bacteria domain, grouped in only one phylum - Proteobacteria. The other $2.55 \%$ sequences remained unclassified. All of the sequences with assigned taxonomy were in the genus Pseudomonas (97.45\%) from the Gammaproteobacteria class. Despite the fact that the AP3 soil sample was extremely reach in terms of bacterial diversity, and only $0.58 \%$ of the sequences from whole sample DNA sequencing were assigned to the Pseudomonas genus, the isolated SDSdegrading microorganisms all belonged to this particular group.

\section{Direct Taxonomic Identification of Isolates of Fast Degraders}

In the last step, detailed classification by Sanger sequencing of cloned 16S rRNA gene amplicons (approximately $1500 \mathrm{bp}$ ) for the five fast-degrading isolates was determined. The alignment of the obtained sequences indicated that the isolates were highly similar to each other but not identical (99.93\% identity for the most similar isolate pair - AP3_10 and AP3_22). The comparison of these sequences to the EzBioCloud database revealed that the four of the fast-degrader isolates showed the highest identity
(AP3_10 - 99.79\%, AP3_16 - 99.24\%, AP3_20 - 99.86\%, and AP3_22 - 99.79\%) to Pseudomonas jessenii CIP 105274. However, the AP3_19 isolate shared the highest identity (99.45\%) with P. mohnii Ipa-2. Figure 4 shows that the entire SDS-degrading group falls within a clade. AP3_10, AP3_16 and AP3_22 isolates clustered with $P$. jessenii CIP 1052274, P. reinekei CCUG 53116, P. koreensis LMG 21318, and P. moraviensis DSM 16007, while AP3_16, and AP3_19 were sister taxa that clustered together in a group that included the previously mentioned clade, plus P. moorei CCUG 53114, and P. vancouverensis DSM 17555. Low bootstrap values cast doubt on the precise relationships among these taxa, and the entire group of interest may also include P. umsongensis LMG 21317 and P. mohnii CCUG 53115. However, it would be an unlikely coincidence for all of these SDS-degrading bacteria to cluster within the same clade, apart from other Pseudomonas bacteria. Above results for the first time indicate that microorganisms from $P$. jessenii subgroup inhabiting terrestrial environment could be involved in SDS degradation.

\section{Characterization of Fast SDS-Degraders}

The most promising isolates belonging to the fast degraders group were examined for: (I) bacterial growth in a range of SDS concentrations, (II) chemotactic response toward SDS, (III) LC-MS/MS analysis of SDS degradation and the identification of the degradation products by SPME-GC-MS, and (IV) Native PAGE zymography to confirm the presence of enzymes involved in SDS degradation.

\section{Effect of SDS Concentration on the Fast Degraders' Growth}

Having bacteria resistant to a high SDS concentration is an important characteristic for bioremediation. To assess the resistance of selected isolates to SDS, an increasing surfactant concentration was supplemented to cultures of each isolate in a range of $0.5-50 \mathrm{~g} / \mathrm{L}$. Bacterial growth, expressed as an increase of optical density (above the initial $\mathrm{OD}_{600}=0.15$ ), was found to be inversely proportional to increasing detergent concentration (Figure 5). All effective degrader isolates reached their highest 


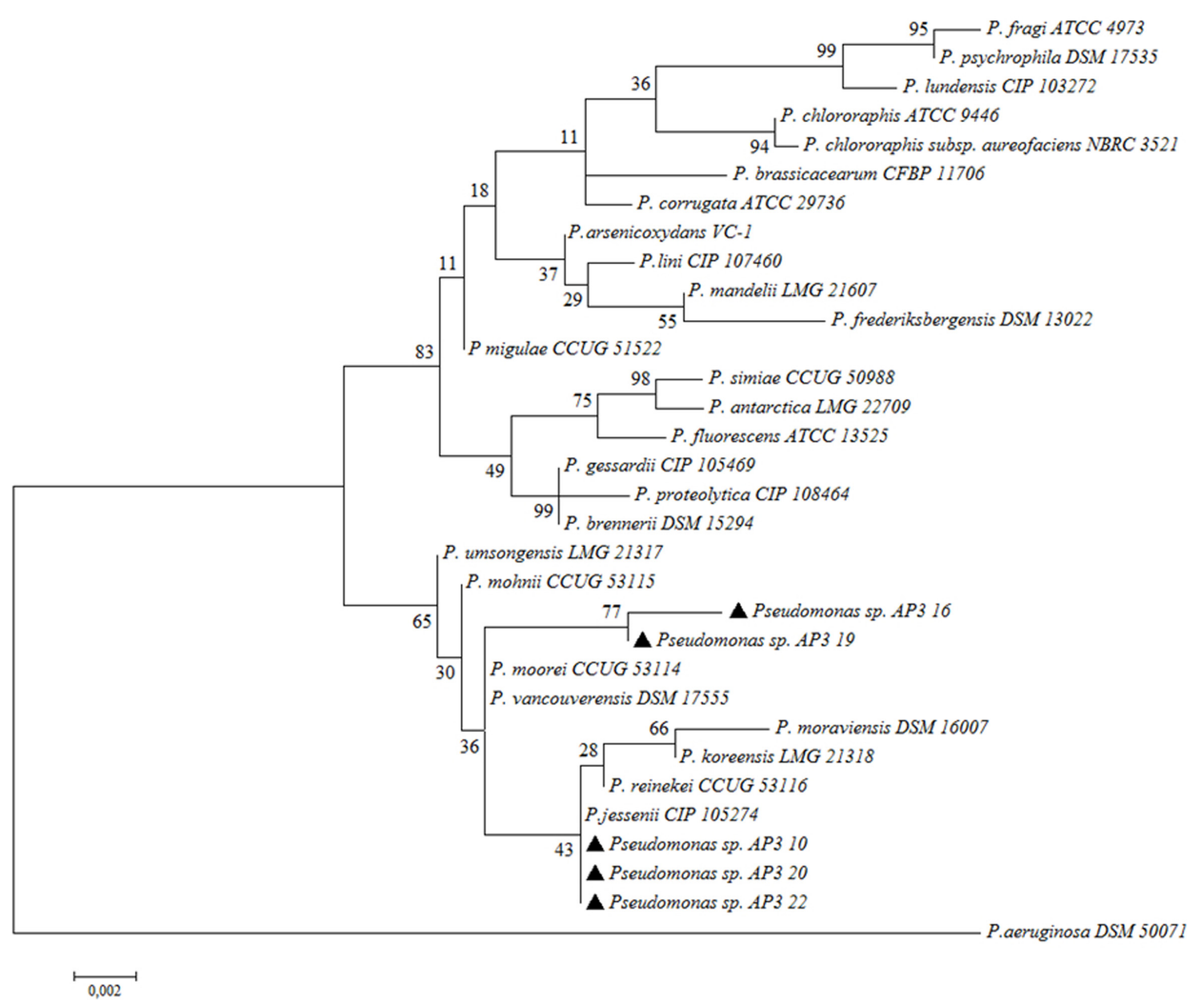

FIGURE 4 | Phylogenetic tree of selected isolates among chosen representatives of Pseudomonas. The phylogenetic tree was computed by Maximum Likelihood with 1,000 bootstrap replicates under an Tamura-Nei model. Examined isolates are marked with black triangles.

optical density $\left(\mathrm{OD}_{600}=0.55-0.75\right)$ in the presence of $1 \mathrm{~g} / \mathrm{L}$ SDS, which could be interpreted as a sign of both a sufficient availability of the carbon source and the minimal negative effects of the detergent. The first SDS toxicity was observed in cultures supplemented by $2.5 \mathrm{~g} / \mathrm{L}$ of SDS, where the optical density for all five isolates was similar or even below the levels observed for $0.5 \mathrm{~g} / \mathrm{L}$ SDS supplemented samples. Presence of $5 \mathrm{~g} / \mathrm{L}$ of detergent in medium had a significant toxic effects on the AP3_10 isolate, as the optical density of this culture did not change after $24 \mathrm{~h}(p$-value $=0.76)$. Meanwhile, isolates AP3_16, AP3_19, AP3_20, and AP3_22 appeared to be relatively resistant in these conditions, as their cultures reached an optical density from 0.22 to 0.4 ( $p$-value $<0.05$ ). In the presence of $10 \mathrm{~g} / \mathrm{L}$ of SDS, only isolate AP3_16 retained an ability to grow $(p$-value $=0.02)$. An intriguing behavior was observed for isolate AP3_16, which in contrast to the other isolates retained an $\mathrm{OD}_{600}$ of 0.12 in the presence of 20 and $25 \mathrm{~g} / \mathrm{L}$ of detergent what was statistically not important change from initial $\mathrm{OD}_{600}=0.15(p$-value $=0.45)$. Such result suggests that this strain maintained the ability at least to survive in the presence of high SDS concentrations, which to our knowledge has not been described before. However, detailed analysis of this phenomenon was not in the main scope of this report and will be investigated in future.

\section{Chemotactic Response of the Isolates toward SDS (Drop Plate Assay)}

The chemotactic response of the five selected isolates toward SDS was studied by a drop plate assay, with glucose as a positive control. Growth rings indicating chemotaxis toward the given carbon source were observed after $8 \mathrm{~h}$ of incubation in the presence of both SDS and glucose (Figure 6). However, detailed analysis of growth patterns revealed differences between the analyzed isolates and carbon sources. On the positive control plates, each isolate migrated up to the center of the dish where the glucose was dropped, whereas on the plates with SDS only isolate AP3_19 exhibited migration up to the dish center. The remaining four isolates grew forming at least one ring of turbidity. For the sister taxa AP3_16, and AP3_19 isolates, which were able to survive at SDS concentrations exceeding $10 \mathrm{~g} / \mathrm{L}$, bacteria grew significantly closer to the plate center where the 

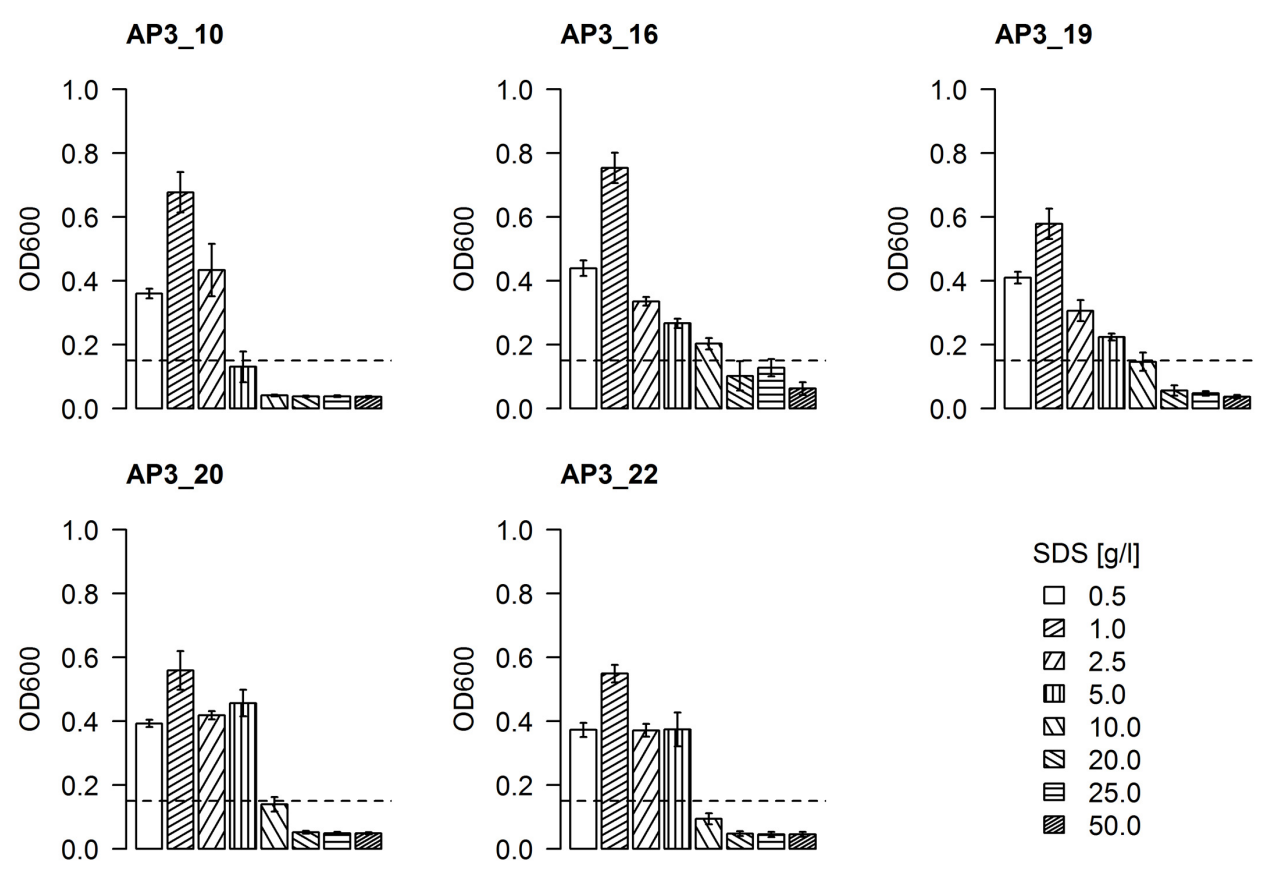

FIGURE 5 | The effect of SDS concentration on the bacterial growth rates of selected strains reflected as optical density of cell cultures after $24 \mathrm{~h}$ of incubation. The values are means of the three replicates, and the error bars indicate the standard deviations. The dotted line represents the initial OD600 of each strain.

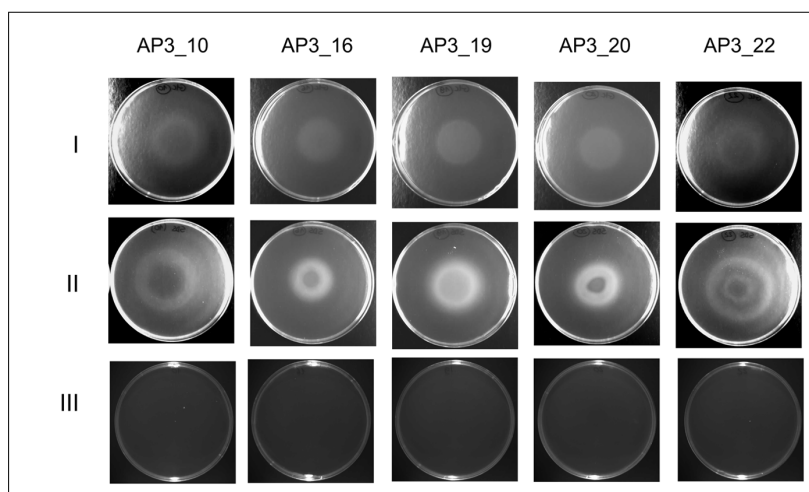

FIGURE 6 | Drop plate assay for bacterial chemotaxis. Pictures of bacterial rings formed after $8 \mathrm{~h}$ incubation at $30^{\circ} \mathrm{C}$. Rows represent selected strains' chemotactic response toward glucose (I), SDS (II) and control plates without compound (III).

detergent was dropped. Whereas, growth rings formed by the SDS-vulnerable AP3_10 and AP3_22 isolates were notably wider, with no sign of bacterial presence in the plate center, where the SDS concentration was the highest. This observation indicate that the AP3_10 and AP3_22 isolates prefer lower detergent concentrations.

\section{Analysis of SDS Degradation by Mass Spectrometry}

For the five selected isolates, we employed mass spectrometry to confirm the SDS-degrading ability observed by colorimetric assay. For this purpose the selected isolates were grown in the same conditions as for colorimetric assay (liquid minimal
TABLE 1 | Sodium dodecyl sulfate (SDS) concentration and $\mathrm{OD}_{600}$ in examined samples after $24 \mathrm{~h}$ of incubation.

\begin{tabular}{lccc}
\hline Strain & \multicolumn{2}{c}{ SDS (g/l) } & OD $_{600}$ \\
& Quantitation method & \\
\cline { 2 - 3 } & Colorimetric assay & LC-MS/MS & \\
\hline AP3_10 & $0.263 \pm 0.013$ & $0.287 \pm 0.012$ & $1.015 \pm 0.008$ \\
AP3_16 & $0.301 \pm 0.002$ & $0.333 \pm 0.050$ & $1.758 \pm 0.013$ \\
AP3_19 & $0.232 \pm 0.013$ & $0.267 \pm 0.015$ & $1.605 \pm 0.015$ \\
AP3_20 & $0.217 \pm 0.012$ & $0.223 \pm 0.032$ & $1.110 \pm 0.016$ \\
AP3_22 & $0.203 \pm 0.011$ & $0.173 \pm 0.021$ & $1.554 \pm 0.004$ \\
Control & $1.096 \pm 0.032$ & $1.17 \pm 0.115$ & 0 \\
\hline
\end{tabular}

Initial SDS concentration in this experiment was $1 \mathrm{~g} / \mathrm{L} \mathrm{SDS}$.

medium supplemented with SDS or glucose as a control as the sole carbon source), and after $24 \mathrm{~h}$ the detergent concentration in the supernatant was confirmed by mass spectrometry. Moreover, the SPME-GC-MS method allowed for the identification of potential SDS degradation products.

\section{LC-MS/MS quantitation of SDS concentration}

The results obtained by LC-MS/MS analysis corresponded with the observations from the colorimetric assay (Table 1). Both methods confirmed a decrease in SDS concentration after incubation with each of the examined isolates. All of the isolates were able to degrade from 70 to $85 \%$ of the detergent during the $24 \mathrm{~h}$ of incubation in the liquid medium containing $1 \mathrm{~g} / \mathrm{L}$ of SDS. Sodium dodecyl sulfate was not detected in the negative control (samples supplemented with glucose). 


\section{SPME-GC-MS metabolites identification}

SPME-GC-MS analysis was chosen for the identification of possible metabolites produced during SDS degradation. Clearly, 1-dodecanol seemed to be the most probable and simple compound belonging to this group. The GC-MS direct injection procedure of the supernatants or non-polar solvent extracts revealed thermal decomposition of SDS in the injection port of the chromatograph, indicating the presence of 1-dodecanol in pure SDS standard samples, thus making it impossible to distinguish the 1-dodecanol derived from biodegradation from that derived from thermal degradation of the analyzed samples. We therefore chose the SPME sample collecting technique, which was previously used with good effect for trace analysis in similar studies (Ouyang et al., 2011). In this technique, the volatile analyte is absorbed onto a coated fiber suspended over the sample in a closed vessel.

No degradation products were absorbed onto the fiber at the beginning of the bacterial growth, nor in the control samples, nor in any samples supplemented with glucose.
However, after $24 \mathrm{~h}$, a single chromatographic peak relating to 1-dodecanol was clearly observed in the GC-MS analysis in all bacterial cultures inoculated with SDS (Figure 7). This strongly suggests that 1 -dodecanol is the main degradation product of SDS decomposition for the chosen bacteria isolates. We could also observe that the levels of identified 1dodecanol varied among the isolates (see Figure 7), however, this observation needs further quantification. Spectra also showed presence of an aldehyde 1-dodecanal, another SDS metabolite, for which peak area was from 20 to 100 times smaller than the peak area observed for the main metabolite 1-dodecanol. What is interesting is that careful analysis of spectra for samples AP3_10, AP3_19, AP3_20, and AP3_22 showed traces of previously undescribed possible metabolites: 2-dodecanol and 3-dodecanol. In contrast, none of these byproducts was identified in the AP3_16 sample - exhibiting the smallest peak related to 1-dodecanol, suggesting that this isolate has the fastest metabolism among the identified isolates.

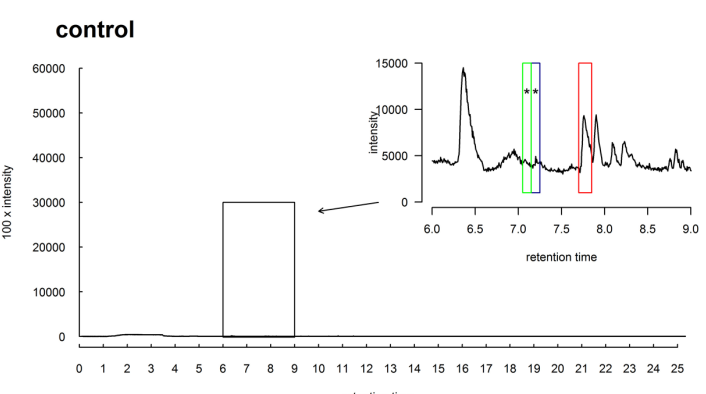

retention time

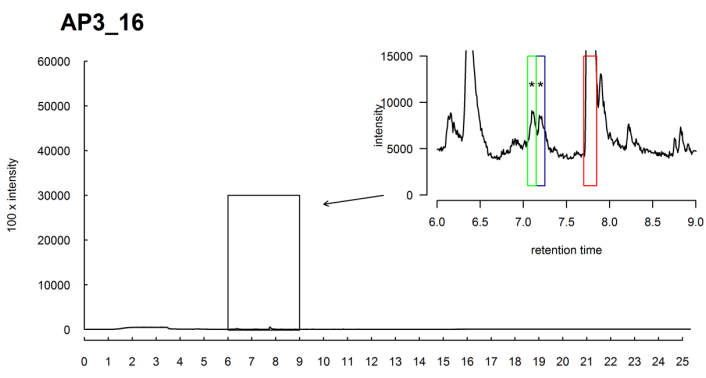

retention time

AP3_20

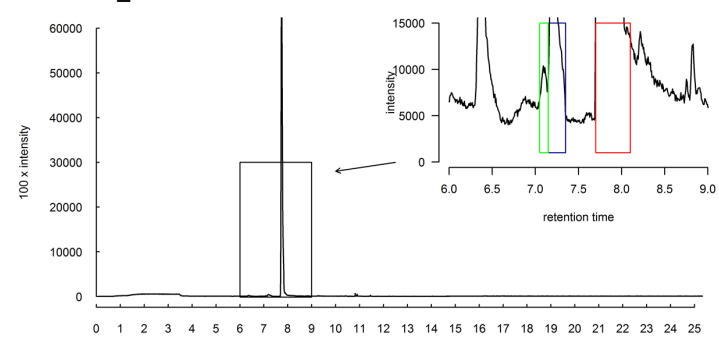

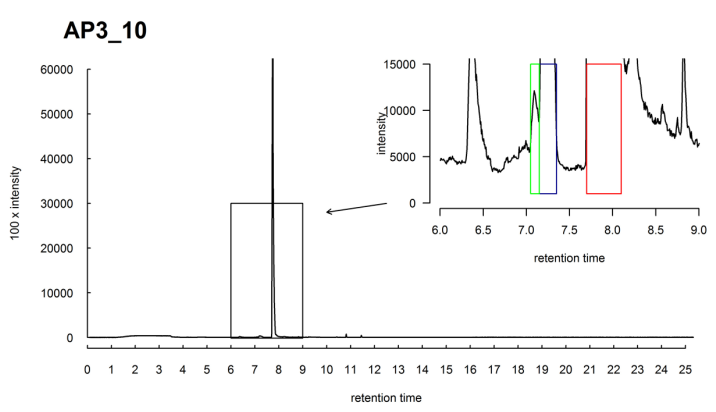

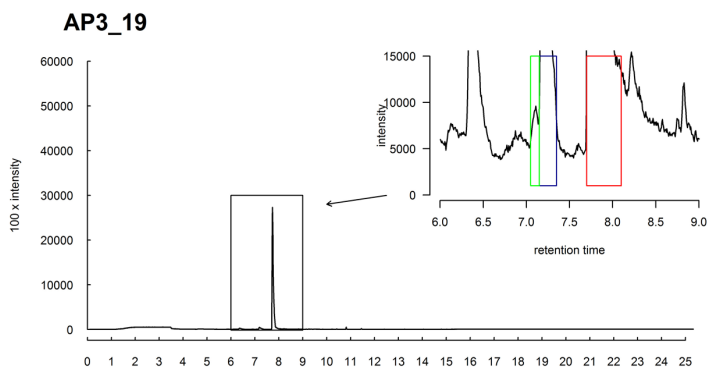

retention time

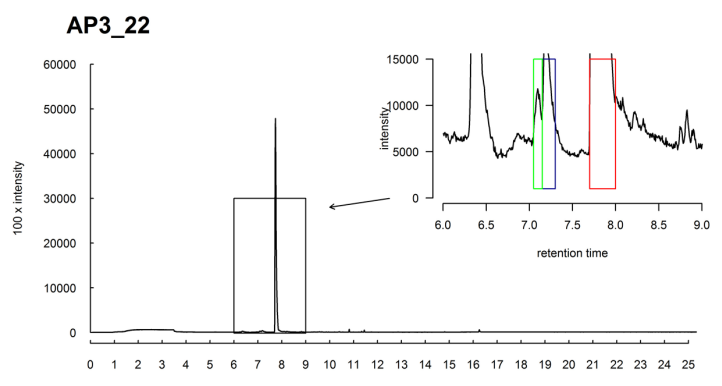

retention time

FIGURE 7 | SPMS-GC-MS analysis of the SDS derivatives for selected strains after $24 \mathrm{~h}$ of incubation in minimal medium supplemented with $1 \mathrm{~g} / \mathrm{L}$ SDS. The boxes indicate the peak positions for: 2-dodecanol and 3-dodecanol (green), dodecanal (blue), and dodecanol (red). MS-data (not-presented) from signals marked with asterisks were insufficient for certain confirmation of the presence of the compounds. However, the accordance of the retention times strongly suggests the presence of traces of these metabolites. 


\section{Detection of Enzymes Engaged in SDS Degradation - Native PAGE Zymography}

SPME-GC-MS analysis revealed 1-dodecanol as the main byproduct formed in the presence of bacteria, which suggests that bacterial alkyl sulfatases could be involved in the metabolism of the detergent. This hypothesis was tested with native PAGE zymography. Native PAGE electrophoresis of crude cell extracts from isolates incubated in the presence of SDS showed presence of visible bands, which indicates that enzymes present in all five tested isolates had the ability for SDS desulfurylation, and thus exhibited alkyl sulfatase activity. Three isolates, AP3_10, AP3_20, and AP3_22, harbored one band on zymography, suggesting the presence of only one enzyme with alkyl sulfatase activity toward SDS (see Figure 8). Whereas for AP3_16 and AP3_19, which are phylogenetically distinct from the others, two bands were visible on zymography, suggesting the presence of two different alkyl sulfatases. Presence of almost all of the identified bands was correlated with the presence of the SDS in the medium. Except AP3_22 sample no activity was detected in cell extracts from isolates cultivated on glucose. Activity observed in the AP3_22 sample was expressed constitutively, and the band appeared on zymography in cell extracts originating from both glucose and SDS cultures.

\section{DISCUSSION}

\section{Properties of the Isolates with Regard to SDS Degradation}

Although all of the isolates described here originated from one soil sample, biochemical tests showed significant differences in their SDS-degrading properties. This diversity was assessed by examination of differences in the halo formed around isolated colonies grown on basal medium supplemented with SDS as the sole carbon source. Further experiments confirmed the abilities of isolates for SDS decomposition and allowed for the identification of the 36 most promising SDS degraders. From this number, AP3_22 turned out to be the most effective isolate, as it decomposed $81 \%$ of $1 \mathrm{~g} / \mathrm{L}$ of SDS within $8 \mathrm{~h}$.

\section{Analysis of the Microbial Taxonomic Biodiversity of the Isolated SDS-Degrading Bacteria and the Soil Sample}

In next step, we wanted to place the isolates that efficiently degrade one of the most popular detergent on the globe into a phylogenetic context. For this purpose, at first we analyzed microbial taxonomic biodiversity of AP3 sample to build the broad picture of the environment inhabited by the isolates. At the same time, we performed a detailed taxonomic classification of the selected isolates to see which microorganisms culturable in laboratory may be involved in sodium dodecyl sulfate decomposition.

Peaty soil analyzed here was inhabited by a diverse microbial consortium grouped in 45 different phyla. This richness was present despite the fact that the soil was regularly contaminated with chemicals like pesticides or detergents. Proteobacteria was the most abundant phylum (33.52\%) in the AP3 soil sample, which stands in accordance to previous reports, where Proteobacteria were found to be the most common phylum for many soil habitats, having a large impact on global carbon, nitrogen, and sulfur cycling (Liles et al., 2003; Tringe et al., 2005; Janssen, 2006; Fulthorpe et al., 2008). Within this phylum Alphaproteobacteria, one of the most abundant bacterial class in soil environments (Spain et al., 2009), was represented in the AP3 sample, consisting of $10.60 \%$ of the sequences. The Gammaproteobacteria consisting of Pseudomonas, Stenotrophomonas, and Sphingomonas, known from their ability to degrade a wide range of chemical compounds of human origin (Spain et al., 2009), were represented by only $0.89 \%$ of sequences in the AP3 sample.

Interestingly, the phylum Parcubacteria seemed to be one of the major phyla in the AP3 soil sample (16.04\%). These uncultured microorganisms are rarely reported in soil or terrestrial environments, and are usually identified in marine and freshwater sediments, mesophilic sulfur springs or lately, in alpine permafrost (Elshahed et al., 2005; Briée et al., 2007; Frey et al., 2016). Microorganisms from this phylum were characterized as having a reduced genome and

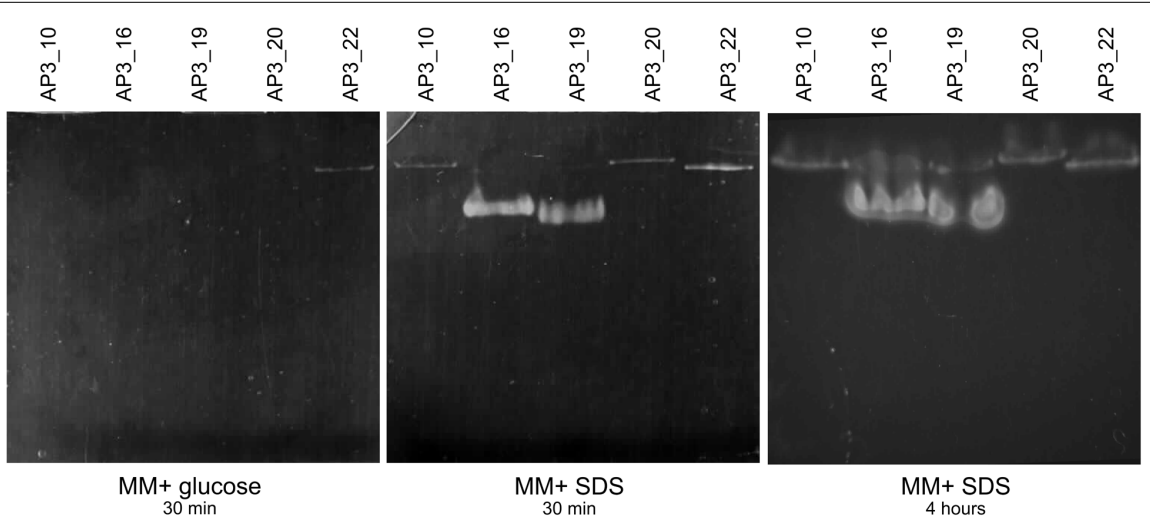

FIGURE 8 | Native PAGE zymography of the five best SDS-degrading strains. 
presumably mutualistic, commensal, or parasitic lifestyles. But until now, there was no evidence showing that microorganisms from phylum Parcubacteria were found in environments contaminated with detergents or other xenobiotics. On the generic level, the AP3 sample showed no dominant group of microorganisms. However, many of them like Crenothrix or Geobacter (Stoecker et al., 2006; Butler et al., 2007; Feld et al., 2015) had been previously isolated from similar soil contaminated environments.

Bioinformatic analysis of the V3-V4 16S rRNA amplicon of the 36 selected SDS degrading isolates revealed that all of the microorganisms presented here belong to Pseudomonas. Surprisingly only $0.58 \%$ of the sequences present in the total DNA were assigned to this genus. This suggests that Pseudomonas could be one of the culturable groups of microorganisms inhabiting analyzed peaty soil, and play an important role in naturally occurring bioremediation of SDS.

Further sequencing of the $16 \mathrm{~S}$ rRNA amplicons of the SDS fast degraders showed that the selected isolates were closely related to $P$. jessenii subgroup. Detailed taxonomic assignment of above isolates has yet to be confirmed; nevertheless, it needs to be emphasized that this is the first time that microorganisms that cluster in the same clade as $P$. jessenii, $P$. moorei, $P$. vancouverensis, $P$. reinekei, $P$. koreensis, and $P$. moraviensis have been shown to have SDS-degrading capabilities. This group may also include $P$. umsongensis, and $P$. mohnii, and is distinct from other Pseudomonas (Figure 4).

This finding sheds more light on the environmental distribution of detergent-degrading Pseudomonas, which up to now have been mainly identified and isolated from samples such as soil, active sludge, and aqueous systems. Moreover, it enlarges the group of known Pseudomonas representatives, such as $P$. aeruginosa, $P$. alcaligenes, $P$. beteli, $P$. mendocina, $P$. otitidis, P. pseudoalcaligenes, $P$. putida, P. plecoglossicida S5, P. stutzeri and other Pseudomonas spp., known to have SDS decomposition abilities (Payne and Feisal, 1963; Kahnert and Kertesz, 2000; Hagelueken et al., 2006; Klebensberger et al., 2006; Jovčić et al., 2009; Chaturvedi and Kumar, 2011b; Yeldho et al., 2011; John et al., 2015).

The previously described $P$. aeruginosa MTCC 10311, isolated from surfactant-contaminated soil, was able to degrade $96 \%$ of $1.5 \mathrm{~g} / \mathrm{L}$ SDS in $48 \mathrm{~h}$ (Ambily and Jisha, 2012), whereas $P$. aeruginosa S7 isolate by Yeldho from contaminated soil degraded 70\% of $1 \mathrm{~g} / \mathrm{L}$ SDS during $24 \mathrm{~h}$ (Yeldho et al., 2011). There were reported several Pseudomonas spp. strains isolated from water ponds in India (Chaturvedi and Kumar, 2010, 2011a) having similar degree of SDS decomposition to the isolates described here.

There were reported several Pseudomonas spp. strains isolated from water ponds in India (Chaturvedi and Kumar, 2010, 2011a) were reported to have a similar degree of SDS decomposition to the isolates described here. The P. putida strain SDS3 and $P$. otitidis strain NN1 identified by Chaturvedi and Kumar degraded $1 \mathrm{~g} / \mathrm{L}$ of SDS almost completely within $12 \mathrm{~h}$. There are also examples of bacteria taxonomically distant to Pseudomonas like A. johnsonii and P. beteli, isolated by Hosseini from active sludge, degrading 96.4 and $97.2 \%$ of $0.522 \mathrm{~g} / \mathrm{L}$ SDS, respectively, within 10 days of incubation in minimal medium (Hosseini et al., 2007). Another example was the $K$. oxytoca isolated from polluted water samples utilized almost $80 \%$ of $2 \mathrm{~g} / \mathrm{L}$ SDS during 4 days of incubation (Shukor et al., 2009). Due to the fact that studies described in the literature have not been performed under similar conditions, it is difficult to compare directly the SDS-degrading capabilities of the Pseudomonas isolates reported here to microorganisms previously described by others. Nevertheless, a literature search showed that isolates from AP3 soil sample, especially AP3_22 belong to the group of the most effective SDS decomposers isolated from terrestrial environments.

\section{Resistance of the Isolates to High SDS Concentrations}

Resistance to the toxic effect of high detergent concentrations is another feature that helps to identify potentially useful detergent-degrading microorganisms. It is known that an SDS concentration exceeding $2 \mathrm{~g} / \mathrm{L}$ kills most bacteria by stripping away the lipopolysaccharide outer layer and denaturing membrane proteins (Odahara, 2004). Our results suggest that two out of five of the identified SDS-degrading isolates have the ability to survive in the presence of $10 \mathrm{~g} / \mathrm{L}$ of SDS. This experiment also showed an intriguing quality of AP3_16. This isolate, retained initial cell culture optical density and cell lysis was not observed in the presence of 20 and $25 \mathrm{~g} / \mathrm{L}$ of detergent. Survival in the presence of such high SDS concentrations has not, to our knowledge, been described before. Moreover, observations from drop plate assays seem to correlate with these results, showing the influence of different SDS concentration on the growth of isolates. Bacteria tolerating SDS concentrations exceeding $10 \mathrm{~g} / \mathrm{L}$ grew significantly closer to the plate center where the detergent was dropped, whereas rings formed by isolates vulnerable to high detergent concentrations were notably wider.

A literature search for the maximum limit of SDS tolerated by Pseudomonas showed that Pseudomonas sp. DRY15, isolated from Antarctic soil, was completely inhibited at $5 \mathrm{~g} / \mathrm{L}$ SDS (Halmi et al., 2013). Whereas $P$. aeruginosa MTCC 10311, identified by Ambily and Jisha (2012), could survive up to $20 \mathrm{~g} / \mathrm{L}$ of SDS.

\section{Analysis of Possible SDS Metabolism By-Products}

The degree of SDS degradation measured with the colorimetric assay was confirmed by the LC-MS/MS method. More importantly, for all five efficient SDS degraders, mass spectrometry (SPME-GC-MS) was employed to analyze the detergent degradation products.

The LC-MS/MS results showed that the colorimetric StainsAll assay, similarly to MBAS (methylene blue active substances assay) method (Shahbazi et al., 2013), may be considered as an inexpensive, fast, and accurate method for sodium dodecyl sulfate quantitation, allowing for easy adaptation to high throughput screening protocols. 
TABLE 2 | Summary of the characteristic of the fast degrader strains.

\begin{tabular}{|c|c|c|c|c|c|}
\hline Strain & AP3_10 & AP3_16 & AP3_19 & AP3_20 & AP3_22 \\
\hline $\begin{array}{l}\text { Closest relative } \\
\text { according to } \\
\text { EzBioCloud database }\end{array}$ & $\begin{array}{l}\text { Pseudomonas jessenii } \\
\text { CIP } 105274\end{array}$ & $\begin{array}{l}\text { Pseudomonas jessenii } \\
\text { CIP } 105274\end{array}$ & $\begin{array}{l}\text { Pseudomonas mohnii } \\
\text { Ipa2 }\end{array}$ & $\begin{array}{l}\text { Pseudomonas jessenii } \\
\text { CIP } 105274\end{array}$ & $\begin{array}{l}\text { Pseudomonas jessenii } \\
\text { CIP } 105274\end{array}$ \\
\hline $\begin{array}{l}\text { Chemotaxis toward } \\
\text { SDS }\end{array}$ & $(+)$ One ring observed & $\begin{array}{l}\text { (+) One ring observed } \\
\text { with almost no empty } \\
\text { space inside }\end{array}$ & $\begin{array}{l}\text { (+) One ring observed } \\
\text { with no empty space } \\
\text { inside }\end{array}$ & (+) One ring observed & (+) Two rings observed \\
\hline Zymography assay & $\begin{array}{l}\text { One band induced by } \\
\text { SDS }\end{array}$ & $\begin{array}{l}\text { Two bands induced by } \\
\text { SDS }\end{array}$ & $\begin{array}{l}\text { Two bands induced by } \\
\text { SDS }\end{array}$ & $\begin{array}{l}\text { One band induced by } \\
\text { SDS }\end{array}$ & One band constitutive \\
\hline $\begin{array}{l}\text { Product of SDS } \\
\text { degradation }\end{array}$ & $\begin{array}{l}\text { Mainly dodecanol; } \\
\text { dodecanal and traces } \\
\text { of 2-dodecanol, } \\
\text { 3-dodecanol }\end{array}$ & Dodecanol & $\begin{array}{l}\text { Mainly dodecanol; } \\
\text { dodecanal and traces } \\
\text { of 2-dodecanol, } \\
\text { 3-dodecanol }\end{array}$ & $\begin{array}{l}\text { Mainly dodecanol; } \\
\text { dodecanal and traces } \\
\text { of 2-dodecanol, } \\
\text { 3-dodecanol }\end{array}$ & $\begin{array}{l}\text { Mainly dodecanol; } \\
\text { dodecanal and traces } \\
\text { of 2-dodecanol, } \\
\text { 3-dodecanol }\end{array}$ \\
\hline $\begin{array}{l}\text { Maximum acceptable } \\
\text { SDS concentration }\end{array}$ & $2.5 \mathrm{~g} / \mathrm{L}$ & $10 \mathrm{~g} / \mathrm{L}$ & $5 \mathrm{~g} / \mathrm{L}$ & $5 \mathrm{~g} / \mathrm{L}$ & $5 \mathrm{~g} / \mathrm{L}$ \\
\hline
\end{tabular}

The SPME-GC-MS analysis confirmed that in the selected five isolates, dodecanol is the main SDS degradation product. However, in the case of isolates: AP3_10, AP3_19, AP3_20, and AP3_22, the SPME-GC-MS method allowed for the identification of low levels of dodecanal, 2-dodecanol, and 3-dodecanol, which could be regarded as SDS degradation by-products. In contrast to previous studies (Thomas and White, 1989; Ambily and Jisha, 2014), we were unable to detect traces of dodecanoic or decanoic acid. This could be explained by the fact that isolates described here were effectively utilizing SDS metabolites as a source of energy or integrating them into cellular membranes. According to Thomas and White (1989), experiments using radiolabeled [1-14C] SDS showed that its degradation is initiated by the sulfatase-mediated hydrolysis of ester to alcohol. Dodecanol is then oxidized to dodecanal, and then further on to dodecanoic acid, which is either elongated to long-chain fatty acids and incorporated into membrane phospholipids or used as an energy source via the tricarboxylic acid cycle.

GC-MS analysis showed that despite the isolates exhibiting a similar degree of SDS bioconversion to dodecanol (measured as a decrease in the substrate concentration), they differed in the levels of this alcohol present in the culture medium after $24 \mathrm{~h}$. Moreover, the ratio of identified dodecanal:dodecanol never exceeded $5 \%$ in any case. The observed differences in the detected dodecanol levels very likely reflect differences in bacterial metabolism.

Interestingly, in the case of the AP3_16 isolate, which had extremely high tolerance to SDS $(25 \mathrm{~g} / \mathrm{L})$, we were unable to detect any derivatives, except low amounts of dodecanol. This could be explained by the fact, that the isolate probably possessing very active enzymatic machinery involved in the subsequent biodegradation steps or an efficient transport system for the derivatives within the bacterial cell. This is probably why even traces of dodecanal, 2-dodecanol, or 3-dodecanol could not be detected in the culture medium after $24 \mathrm{~h}$ of AP3_16 incubation with SDS.

On the other hand, in samples from the AP3_10 isolate, one of the less tolerant toward SDS (growing only up to $2.5 \mathrm{~g} / \mathrm{L}$ ), we could observe all of the aforementioned compounds with relatively high amounts of dodecanol.

\section{Identification of Alkylsulfatase Activity in the Isolates}

Native PAGE zymography revealed that all of the selected isolates possessed alkylsulfatase-like activity. Three isolates, AP3_10, AP3_20, and AP3_22, produced a single band that could be the result of alkylsulfatase activity, whereas for isolates AP3_16 and AP3_19 two bands were observed. Intriguingly, there was no correlation between the number of identified potential alkyl sulfatases and the SDS degradation products observed with SPME-GC-MS. Several previously published reports suggest that microorganisms involved in SDS degradation could produce single (Hagelueken et al., 2006; Chaturvedi and Kumar, 2010, 2011b; Jovcic et al., 2010) or multiple alkylsulfatases, such as Pseudomonas C12B - five enzymes or P. putida FLA - six enzymes (Lillis et al., 1983). Our results also suggest that the alkyl sulfatase activity in four out of the five tested isolates is regulated by the presence of SDS in the culture media, similar to the results obtained by, for instance, Chaturvedi and Kumar (2010). However, the AP3_22 isolate harbored a constitutively expressed alkyl sulfatase, such as the P1 sulfatase from Pseudomonas C12B (Toesch et al., 2014).

\section{CONCLUSION}

In this study, we used peaty soil sampled from a biological wastewater treatment plant to isolate and identify 36 Pseudomonas isolates exhibiting the ability to use SDS as their sole carbon source. Five isolates, having close taxonomic relationships to $P$. jessenii, $P$. moorei, $P$. vancouverensis, $P$. reinekei, $P$. koreensis, and $P$. moraviensis appeared to be the most efficient SDS degraders, decomposing from 80 to $100 \%$ of the SDS present at an initial concentration $1 \mathrm{~g} / \mathrm{L}$ within $24 \mathrm{~h}$. Despite their similarity, all isolates belonging to the $P$. jessenii subgroup exhibited significant differences in the dynamics of their SDS degradation, chemotaxis toward SDS on a plate test, and resistance to high detergent concentrations (see Table 2). The detergent metabolism among these five effectively degrading isolates was reflected by the byproducts observed with mass 
spectrometry, where beside the dominating and well-known 1-dodecanol, we observed traces of dodecanal, 2-dodecanol, and 3-dodecanol, but no dodecanoic acid. The discrepancy between the isolates identified here was confirmed by a zymography test that strongly suggested that the closely related microorganisms isolated from one soil sample employed more than one alkyl sulfatase for SDS desulfurylation, which is considered as the initial step for detergent decomposition. The above observations indicate that isolates described here exhibit exceptional capabilities for detergent decomposition and have developed very efficient mechanisms to survive and flourish in very high SDS concentrations. In order to better describe the above phenomena, we plan to extend the analysis at the genomic and metabolomic levels. Analysis of the complete genome sequence of these microorganisms could allow us to identify alkyl sulfatase enzymes, which are responsible for SDS decomposition. Moreover, genome analysis will be helpful to decipher mechanisms that allow those microorganisms to survive in presence of SDS exceeding $10 \mathrm{~g} / \mathrm{L}$. Future discoveries will open a way to develop biochemical tools to manage SDS in either natural or industrial environments.

\section{AUTHOR CONTRIBUTIONS}

AS and LL conceived and directed the studies. MK participated in bacteria isolation from soil. Bacterial phenotype analysis,

\section{REFERENCES}

Abboud, M. M., Khleifat, K. M., Batarseh, M., Tarawneh, K. A., Al-Mustafa, A., and Al-Madadhah, M. (2007). Different optimization conditions required for enhancing the biodegradation of linear alkylbenzosulfonate and sodium dodecyl sulfate surfactants by novel consortium of Acinetobacter calcoaceticus and Pantoea agglomerans. Enzyme Microb. Technol. 41, 432-439. doi: 10.1016/j.enzmictec.2007.03.011

Ambily, P. S., and Jisha, M. S. (2012). Biodegradation of anionic surfactant, sodium dodecyl sulphate by Pseudomonas aeruginosa MTCC 10311. J. Environ. Biol. 33, 717-720.

Ambily, P. S., and Jisha, M. S. (2014). Metabolic profile of sodium dodecyl sulphate (SDS) biodegradation by Pseudomonas aeruginosa (MTCC 10311). J. Environ. Biol. 35, 827-831.

Briée, C., Moreira, D., and López-García, P. (2007). Archaeal and bacterial community composition of sediment and plankton from a suboxic freshwater pond. Res. Microbiol. 158, 213-227. doi: 10.1016/j.resmic.2006. 12.012

Butler, J. E., He, Q., Nevin, K. P., He, Z., Zhou, J., and Lovley, D. R. (2007). Genomic and microarray analysis of aromatics degradation in Geobacter metallireducens and comparison to a Geobacter isolate from a contaminated field site. BMC Genomics 8:180. doi: 10.1186/14712164-8-180

Caporaso, J. G., Kuczynski, J., Stombaugh, J., Bittinger, K., Bushman, F. D., Costello, E. K., et al. (2010). QIIME allows analysis of high-throughput community sequencing data. Nat. Methods 7, 335-336. doi: 10.1038/nmeth.f. 303.QIIME

Chaturvedi, V., and Kumar, A. (2010). Isolation of sodium dodecyl sulfate degrading strains from a detergent polluted pond situated in Varanasi city, India. J. Cell Mol. Biol. 8, 103-111.

Chaturvedi, V., and Kumar, A. (2011a). Diversity of culturable sodium dodecyl sulfate (SDS) degrading bacteria isolated from detergent contaminated ponds situated in Varanasi city, India. Int. Biodeterior. Biodegrad. 65, 961-971. doi: 10.1016/j.ibiod.2011.07.005
DNA isolation, DNA libraries preparation, amplicon sequencing and all bioinformatics analysis were performed by EF. GS, MS, and WD designed and performed the LC-MS/MS and SPME-GC-MS analysis with MS data interpretation. The manuscript was written by EF, consulted and corrected by AS, LL, and AD. Funding for this work was provided by LL and AD. All the authors read and approved the final manuscript.

\section{FUNDING}

This work was supported by the European Regional Development Fund, the Operational Program Innovative Economy 2007-2013, the project support Agreement POIG.01.01.0214-054/09-00. Experiments were carried out with the use of CePT infrastructure financed by the European Unionthe European Regional Development Fund [Innovative economy 2007-2013, Agreement POIG.02.02.00-14-024/ 08-00].

\section{SUPPLEMENTARY MATERIAL}

The Supplementary Material for this article can be found online at: https://www.frontiersin.org/articles/10.3389/fmicb. 2017.01872/full\#supplementary-material

Chaturvedi, V., and Kumar, A. (2011b). Isolation of a strain of Pseudomonas putida capable of metabolizing anionic detergent sodium dodecyl sulfate (SDS). Iran. J. Microbiol. 3, 47-53.

Cserhati, T., Forgacs, E., and Oros, G. (2002). Biological activity and environmental impact of anionic surfactants. Environ. Int. 28, 337-348. doi: 10.1016/S01604120(02)00032-6

Edgar, R. C. (2010). Search and clustering orders of magnitude faster than BLAST. Bioinformatics 26, 2460-2461. doi: 10.1093/bioinformatics/ btq461

Eerlingen, R. C., Cillen, G., and Delcour, J. A. (1994). Enzyme-Resistant Starch. IV. Effect of endogenous lipids and added sodium dodecyl sulfate on formation of resistant starch. Cereal Chem. 71, 170-177.

Elshahed, M. S., Najar, F. Z., Aycock, M., Qu, C., Roe, B. A., and Krumholz, L. R. (2005). Metagenomic analysis of the microbial community at Zodletone Spring (Oklahoma): insights into the genome of a member of the novel candidate division OD1. Appl. Environ. Microbiol. 71, 7598-7602. doi: 10.1128/AEM.71. 11.7598-7602.2005

Feld, L., Nielsen, T. K., Hansen, L. H., Aamand, J., and Albers, C. N. (2015). Establishment of bacterial herbicide degraders in a rapid sand filter for bioremediation of phenoxypropionate-polluted groundwater. Appl. Environ. Microbiol. 82, 878-887. doi: 10.1128/AEM.02600-15

Frey, B., Rime, T., Phillips, M., Stierli, B., Hajdas, I., Widmer, F., et al. (2016). Microbial diversity in European alpine permafrost and active layers. FEMS Microbiol. Ecol. 92, 1-17. doi: 10.1093/femsec/fiw018

Fulthorpe, R. R., Roesch, L. F. W., Riva, A., and Triplett, E. W. (2008). Distantly sampled soils carry few species in common. ISME J. 2, 901-910. doi: 10.1038/ ismej.2008.55

Hagelueken, G., Adams, T. M., Wiehlmann, L., Widow, U., Kolmar, H., Tummler, B., et al. (2006). The crystal structure of SdsA1, an alkylsulfatase from Pseudomonas aeruginosa, defines a third class of sulfatases. Proc. Natl. Acad. Sci. U.S.A. 103, 7631-7636. doi: 10.1073/pnas.0510501103

Halmi, M., Hussin, W., Aqlima, A., Syed, M., Ruberto, L., MacCormack, W., et al. (2013). Characterization of a sodium dodecyl sulphate-degrading Pseudomonas sp. strain DRY15 from Antarctic soil. J. Environ. Biol. 34, 1077-1082. 
Hosseini, F., Malekzadeh, F., Amirmozafari, N., and Ghaemi, N. (2007). Biodegradation of anionic surfactants by isolated bacteria from activated sludge. Int. J. Environ. Sci. Tech. 4, 127-132. doi: 10.1007/BF03325970

Im, S. H., Jeong, Y. H., and Ryoo, J. J. (2008). Simultaneous analysis of anionic, amphoteric, nonionic and cationic surfactant mixtures in shampoo and hair conditioner by RP-HPLC/ELSD and LC/MS. Anal. Chim. Acta 619, 129-136. doi: 10.1016/j.aca.2008.03.058

Ivanković, T., and Hrenović, J. (2010). Surfactants in the environment. Arh. Hig. Rada. Toksikol. 61, 95-110. doi: 10.2478/10004-1254-61-2010-1943

Janssen, P. H. (2006). Identifying the dominant soil bacterial taxa in libraries of 16S rRNA and 16S rRNA Genes. Appl. Environ. Microbiol. 72, 1719-1728. doi: 10.1128/AEM.72.3.1719

John, E. M., Sharrel, J., Asok, A. K., and Jisha, M. S. (2015). Pseudomonas plecoglossicida $\mathrm{S} 5$, a novel nonpathogenic isolate for sodium dodecyl sulfate degradation. Environ. Chem. Lett. 13, 117-123. doi: 10.1007/s10311-0150493-7

Jovčić, B., Begović, J., Lozo, J., Topisirović, L., and Kojić, M. (2009). Dynamics of sodium dodecyl sulfate utilization and antibiotic susceptibility of strain Pseudomonas sp. ATCC19151. Arch. Biol. Sci. 61, 154-164. doi: 10.2298/ ABS0902159J

Jovcic, B., Venturi, V., Davison, J., Topisirovic, L., and Kojic, M. (2010). Regulation of the sdsA alkyl sulfatase of Pseudomonas sp. ATCC19151 and its involvement in degradation of anionic surfactants. J. Appl. Microbiol. 109, 1076-1083. doi: $10.1111 / j .1365-2672.2010 .04738 . x$

Kahnert, A., and Kertesz, M. A. (2000). Characterization of a sulfur-regulated oxygenative alkylsulfatase from Pseudomonas putida S-313. J. Biol. Chem. 275, 31661-31667. doi: 10.1074/jbc.M005820200

Klebensberger, J., Rui, O., Fritz, E., Schink, B., and Bodo, P. (2006). Cell aggregation of Pseudomonas aeruginosa strain $\mathrm{PAO} 1$ as an energy-dependent stress response during growth with sodium dodecyl sulfate. Arch. Microbiol. 185 417-427. doi: 10.1007/s00203-006-0111-y

Klindworth, A., Pruesse, E., Schweer, T., Peplies, J., Quast, C., Horn, M., et al. (2013). Evaluation of general $16 \mathrm{~S}$ ribosomal RNA gene PCR primers for classical and next-generation sequencing-based diversity studies. Nucleic Acids Res. 41:e1. doi: 10.1093/nar/gks808

Lane, D. J. (1991). "16S/23S rRNA sequencing," in Nucleic Acid Techniques in Bacterial Systematics, eds E. Stackebrandt and M. Goodfellow (New York, NY: John Wiley and Sons), 115-175.

Larkin, M. A., Blackshields, G., Brown, N. P., Chenna, R., Mcgettigan, P. A., McWilliam, H., et al. (2007). Clustal W and Clustal X version 2.0. Bioinformatics 23, 2947-2948. doi: 10.1093/bioinformatics/btm 404

Lechuga, M., Fernández-serrano, M., Jurado, E., and Ríos, F. (2016). Acute toxicity of anionic and non-ionic surfactants to aquatic organisms. Ecotoxicol. Environ. Saf. 125, 1-8. doi: 10.1016/j.ecoenv.2015.11.027

Liles, M. R., Manske, B. F., Bintrim, S. B., Handelsman, J., and Goodman, R. M. (2003). A census of rRNA genes and linked genomic sequences within a soil metagenomic library. Appl. Environ. Microbiol. 69, 2684-2691. doi: 10.1128/ AEM.69.5.2684

Lillis, V., Dodgson, K. S., White, G. F., and Payne, W. J. (1983). Initiation of activation of a preemergent herbicide by a novel alkylsulfatase of Pseudomonas putida FLA. Appl. Environ. Microbiol. 46, 988-994.

Magoč, T., and Salzberg, S. L. (2011). FLASH: fast length adjustment of short reads to improve genome assemblies. Bioinformatics 27, 2957-2963. doi: 10.1093/ bioinformatics/btr507

Martin, M. (2011). Cutadapt removes adapter sequences from high-throughput sequencing reads. EMBnet J. 17, 10-12. doi: 10.14806/ej.17.1.200

Masdor, N., Shukor, M. Shukri A., Khan, A., Bin Halmi, M. I. E., Abdullah, S. R. S., Shamaan, N. A., et al. (2015). Isolation and characterization of a molybdenum-reducing and SDS- degrading Klebsiella oxytoca strain Aft-7 and its bioremediation application in the environment. Biodiversitas 16, 238-246. doi: $10.13057 /$ biodiv/d160219

Moldes, A. B., Paradelo, R., Vecino, X., Cruz, J. M., Gudiña, E., Rodrigues, L., et al. (2013). Partial characterization of biosurfactant from lactobacillus pentosus and comparison with sodium dodecyl sulphate for the bioremediation of hydrocarbon contaminated soil. Biomed. Res. Int. doi: 10.1155/2013/961842

Nelson, W. C., and Stegen, J. C. (2015). The reduced genomes of Parcubacteria ( OD1 ) contain signatures of a symbiotic lifestyle. Front. Microbiol. 6:713. doi: $10.3389 /$ fmicb.2015.00713
Odahara, T. (2004). Stability and solubility of integral membrane proteins from photosynthetic bacteria solubilized in different detergents. Biochim. Biophys. Acta Biomembr. 1660, 80-92. doi: 10.1016/j.bbamem.2003.11.003

Ouyang, G., Vuckovic, D., and Pawliszyn, J. (2011). Nondestructive sampling of living systems using in vivo solid-phase microextraction. Chem. Rev. 111, 2784-2814. doi: 10.1021/cr100203t

Payne, W. J., and Feisal, V. E. (1963). Bacterial utilization of dodecyl sulfate and dodecyl benzene sulfonate. Appl. Microbiol. 11, 339-344.

Quast, C., Pruesse, E., Yilmaz, P., Gerken, J., Schweer, T., Glo, F. O., et al. (2013). The SILVA ribosomal RNA gene database project?: improved data processing and web-based tools. Nucleic Acids Res. 41, 590-596. doi: 10.1093/nar/ gks1219

Rahman, M., Rusnam, M., Gusmanizar, N., Masdor, N., Lee, C. H., Shukor, M. S., et al. (2016). Molybdate-reducing and SDS-degrading Enterobacter sp. strain neni-13. Nov. Biotechnol. Chim. 15, 166-181. doi: 10.1515/nbec-2016-0017

Rusconi, F., Valton, E., Nguyen, R., and Dufourc, E. (2001). Quantification of sodium dodecyl sulfate in microliter-volume biochemical samples by visible light spectroscopy. Anal. Biochem. 295, 31-37. doi: 10.1006/abio.2001.5164

Sambrook, J., and Russel, D. (2001). Molecular Cloning: A Laboratory Manual. New York, NY: Cold Spring Harbor Laboratory Press.

Sandbacka, M., Christianson, I., and Isomaa, B. (2000). The acute toxicity of surfactants on fish cells, Daphnia magna and fish-A comparative study. Toxicol. Vitro 14, 61-68. doi: 10.1016/S0887-2333(99)00083-1

Shahbazi, R., Kasra-kermanshahi, R., Gharavi, S., Nejad, Z. M., and Borzooee, F. (2013). Screening of SDS-degrading bacteria from car wash wastewater and study of the alkylsulfatase enzyme activity. Iran. J. Microbiol. 5, 153-158.

Shukor, M. Y., Husin, W. S. W., Rahman, M. F. A., Shamaan, N. A., and Syed, M. A. (2009). Isolation and characterization of an SDS-degrading Klebsiella oxytoca. J. Environ. Biol. 30, 129-134.

Spain, A. M., Krumholz, L. R., and Elshahed, M. S. (2009). Abundance, composition, diversity and novelty of soil Proteobacteria. ISME J. 3, 992-1000. doi: 10.1038 /ismej.2009.43

Stoecker, K., Bendinger, B., Schoning, B., Nielsen, P. H., Nielsen, J. L., Baranyi, C., et al. (2006). Cohn' s crenothrix is a filamentous methane oxidizer with an unusual methane monooxygenase. Proc. Natl. Acad. Sci. U.S.A. 103, 2363-2367. doi: 10.1073/pnas.0506361103

Tamura, K., Stecher, G., Peterson, D., Filipski, A., and Kumar, S. (2013). MEGA6: molecular evolutionary genetics analysis version 6.0. Mol. Biol. Evol. 30, 2725-2729. doi: $10.1093 / \mathrm{molbev} / \mathrm{mst} 197$

Thomas, O. R, and White, G. F. (1989). Metabolic pathway for the biodegradation of sodium dodecyl sulfate by Pseudomonas sp. C12B. Biotechnol. Appl. Biochem. $11,318-327$.

Toesch, M., Schober, M., and Faber, K. (2014). Microbial alkyl- and aryl-sulfatases: mechanism, occurrence, screening and stereoselectivities. Appl. Microbiol. Biotechnol. 98, 1485-1496. doi: 10.1007/s00253-013-5438-0

Tringe, S. G., von Mering, C., Kobayashi, A., Salamov, A. A., Chen, K., Chang, H. W., et al. (2005). Comparative metagenomics of microbial communities. Science 308, 554-557. doi: 10.1126/science.1107851

Wang, Q., Garrity, G. M., Tiedje, J. M., Cole, J. R., and Al, W. E. T. (2007). Naive Bayesian classifier for rapid assignment of rRNA sequences into the new bacterial taxonomy? †. Appl. Environ. Microbiol. 73, 5261-5267. doi: 10.1128/ AEM.00062-07

Yeldho, D., Rebello, S., and Jisha, M. S. (2011). Plasmid-mediated biodegradation of the anionic surfactant sodium dodecyl sulphate, by Pseudomonas aeruginosa S7. Bull. Environ. Contam. Toxicol. 86, 110-113. doi: 10.1007/s00128-0100162-2

Yoon, S., Ha, S., Kwon, S., Lim, J., Kim, Y., Seo, H., et al. (2017). Introducing EzBioCloud?: a taxonomically united database of $16 \mathrm{~S}$ rRNA gene sequences and whole-genome assemblies. Int. J. Syst. Evol. Microbiol. 67, 1613-1617. doi: 10.1099/ijsem.0.001755

Yu, H., Zhu, L., and Zhou, W. (2007). Enhanced desorption and biodegradation of phenanthrene in soil-water systems with the presence of anionic-nonionic mixed surfactants. J. Hazard. Mater. 142, 354-361. doi: 10.1016/j.jhazmat.2006. 08.028

Zangeneh, H., Zinatizadeh, A. A. L., and Feizy, M. (2014). A comparative study on the performance of different advanced oxidation processes $\left(\mathrm{UV} / \mathrm{O} 3 / \mathrm{H}_{2} \mathrm{O}_{2}\right)$ treating linear alkyl benzene (LAB) production plant's 
wastewater. J. Ind. Eng. Chem. 20, 1453-1461. doi: 10.1016/j.jiec.2013. 07.031

Zhou, J., Bruns, M. A., and Tiedje, J. M. (1996). DNA recovery from soils of diverse composition. Appl. Environ. Microbiol. 62, 316-322.

Zhou, W., and Zhu, L. (2008). Enhanced soil flushing of phenanthrene by anionicnonionic mixed surfactant. Water Res. 42, 101-108. doi: 10.1016/j.watres.2007. 07.021

Conflict of Interest Statement: The authors declare that the research was conducted in the absence of any commercial or financial relationships that could be construed as a potential conflict of interest.
The reviewer $\mathrm{CP}$ and handling Editor declared their shared affiliation, and the handling Editor states that the process nevertheless met the standards of a fair and objective review.

Copyright (c) 2017 Furmanczyk, Kaminski, Spolnik, Sojka, Danikiewicz, Dziembowski, Lipinski and Sobczak. This is an open-access article distributed under the terms of the Creative Commons Attribution License (CC BY). The use, distribution or reproduction in other forums is permitted, provided the original author(s) or licensor are credited and that the original publication in this journal is cited, in accordance with accepted academic practice. No use, distribution or reproduction is permitted which does not comply with these terms. 